\title{
Sliding Mode Control of Hybrid Renewable Energy System Operating in Grid Connected and Stand-Alone Mode
}

Research Article

\author{
Ridha Benadli1 ${ }^{*} \odot$, Marwen Bjaoui², Brahim Khiari ${ }^{3}$, Anis Sellami ${ }^{4}$ \\ 1 LANSER Laboratory/CRTEn B.P.95 Hammam-Lif 2050, Tunis-Tunisia \\ 2 LANSER Laboratory/CRTEn B.P.95 Hammam-Lif 2050, Tunis-Tunisia \\ ${ }^{3}$ LANSER Laboratory/CRTEn B.P.95 Hammam-Lif 2050, Tunis-Tunisia \\ ${ }^{4}$ Research unit: LISIER, National Higher Engineering School of Tunis, Tunis-Tunisia
}

Received: July 14, 2021; Accepted: August 11, 2021

\begin{abstract}
This paper studies innovative application of sliding mode control (SMC) for a Hybrid Renewable Energy System (HRES) in gridconnected and autonomous modes of operation. The considered HRES includes a photovoltaic (PV), wind turbine (WT) based on a Permanent Magnet Synchronous Generator (PMSG). The PV generator is coupled to the common DC bus via a DC/DC converter. The latter is controlled by an MPPT algorithm based on the Adaptive Perturbation and Observation Algorithm Method (APOAM) to search the optimum working of this source. A SMC is utilized to manage the PV voltage to achieve the Maximum Power Point (MPP) by altering the obligation duty cycle. The battery interfaced by a bidirectional buck-boost DC/DC converter can be charged or discharged depending on the production situation. On the one hand, the wind turbine conversion chain is equipped with a PMSG and a rectifier controlled to regulate the operating point of the wind turbine to its optimum value. During a Stand-Alone Mode (SAM) operation, the Voltage Source Converter (VSC) was used for controlling the output voltage in terms of amplitude and frequency delivered to the AC load. However, in Grid-Connected Mode (GCM) operation, the VSC was adapted to control the electrical parameters of the grid. To better appreciate the advantages of the proposed SMC approach, we have proposed a series of comparative tests with the conventional $\mathrm{PI}$ control in the operating modes GC and SA and under different scenarios. The proposed control strategy has undeniable advantages in terms of control performance and very low total harmonic distortion THD value compared with the conventional PI control. Finally, It is concluded that the proposed approach improves the quality and provides a stable operation of the HRES.
\end{abstract}

Keywords: sliding mode control • grid-connected mode $\bullet$ stand-alone mode $\bullet$ hybrid renewable energy system $\bullet$ wind turbine $\bullet$ photovoltaic - battery energy storage system • maximum power point tracking

\section{Introduction}

A hybrid system interconnected by a set of Renewable Energy Resources (RES) and storage systems helps to ensure greater energy availability and optimize maximum power generation systems from both, technical and economic points of view. The hybrid photovoltaic/wind/battery systems are becoming a very attractive cost-competitive solution used in both stand-alone and grid-connected applications (Bhandari, 2015; Arul, 2015). Reviews of the literature on the optimization and control of hybrid photovoltaic/wind systems were conducted in (Luna, 2012; Arul, 2015). The authors claimed that the performance of a hybrid PV/wind system is better than that of wind and PV systems. In the references (Ahmed 2008; Bae,2012), the authors reported that the integration of these two sources (wind and photovoltaic) with BESS makes it possible to better benefit from each of the sources, to offer better reliability and reduce environmental impacts such as greenhouse gas emissions. During the last decade, the exploitation RES of in power generation has become increasingly important due to the availability of these two resources in most of the world and also to the attenuated decrease in their cost of installation. Other reinforcement sources can be

\section{*Email: ridhabenadly@gmail.com}

O Open Access. ๑ 2021 Benadli et al., published by Sciendo. (G) Br-Nc-ND This work is licensed under the Creative Commons Attribution NonCommercial-NoDerivatives 4.0 License. 
utilized for the creation of sustainable wellsprings of empty periods with or without battery like (Bouharchouche, 2013; Jayalakshmi, 2016), power modules super-capacitors, the vitality stockpiling flywheel, and diesel generators.

The main objective of controlling a VSC in a SAM operation is to regulate the voltage and frequency of the AC bus ensuring good quality of the energy demanded by the AC loads and to provide sinusoidal current in phase with the load voltage having low total harmonic distortion (THD). Since the nature of the output voltage VSC is intensely influenced by the nature of loads. So, the performance of the control strategy applied to this converter is very dependent on the dynamic characteristics of the loads. Many studies on control strategies have been carried out in various publications to improve the performance of VSC (Malinowski, 2003; Larrinaga, 2007; Rodriguez, 2007; He, 2018). Ref (Benadli, 2020) was presented a PI method to control the VSC for a PV/WT/battery hybrid system. In this case, the frequency and voltage regulation was performed but the non-linear load and unbalanced load are not considered which will make the system unreliable. In (Malla, 2014; Boukettaya, 2014) a conventional PI controller was explored to control the VSC system operating in SAM with a reasonably adjusted load condition. However, this control technique cannot cover varieties of substantial load and its THD is not acceptable due to the precedence of nonlinear loads).

For a VSC connected to the grid, the objective of controlling is to achieve the exchange of the required power, to provide sinusoidal current waveforms with low THD. As in a stand-alone VSC, the performance of the system depends largely on the control strategy applied to the VSC. Many studies on control strategies have been carried out in various publications to improve the performance of a grid-connected VSC (Benadli, 2015). The common goal of all these strategies is to obtain a power factor very close to unity, good DC bus regulation and low current THD. One of the most popular techniques used for controlling the electrical parameters of the grid greatness VSC is the Voltage Oriented Control (VOC). It generally guarantees stability, acceptable dynamics and good performance through the loop of current internal regulations (Benadli, 2019). However, the application of classical PI regulators in this scheme results in poor dynamic performance and poor stability of the overall system.

The PV system is generally composed of a PV generator coupled to the DC bus via a boost DCDC controlled by MPPT method. The aim of this latter is to maximize the power of the PV source under normal operating conditions of the HRES. In the literature, different MPPT techniques have been proposed to search for maximum power points in stand-alone or grid-connected PV systems. The techniques most used in the literature are P\&O (Malla, 2014; Madaci, 2016) and Incremental Conductance (IC) (Benadli, 2015) because they have structures that are simple to understand and easy to implement in practice (Bouharchouche, 2013). However, these algorithms cannot function properly under rapid changes in environmental conditions. Indeed, they present oscillations at the MPP under stable conditions. These methods also exhibit, during variations in meteorological conditions, a slow or even divergent convergence speed (Dileep, 2017).

The most common solution is to implement a two-stage control structure using a classic MPPT algorithm, such as Perturb and Observe P\&O or IC in cascade with a PV generator voltage and/or current regulator based on the PI regulator (Elgendy, 2011; Ahmed, 2008; Dali, 2010). However, the effectiveness of these methods strongly depends on the MPPT parameters used, while the stability of MPPT controllers also depends on the type of regulator often used to regulate current or voltage to a variable reference obtained with another conventional MPPT method. This makes it difficult to guarantee the system stability and obtain the desired performance under all conditions of operation of the hybrid system. To maximize the amount of power supplied by the PV module, it is necessary to force the PV panel to operate at the MPP of the supply voltage characteristic of the PV generator. This characteristic has a MPP that can be provided by the P\&O method. The purpose of the control is to force the output to follow this reference value to ensure optimum power extraction. The application of the P\&O method with an adaptive gain provides acceptable dynamic performance to maximize power under disturbances and climatic variations (Elgendy, 2011). In this study, we implemented a two-stage control structure using a classic $P \& O$ with an adaptive gain cascade algorithm with a voltage regulator based on a sliding mode regulator. This method is applied to the boost $\mathrm{DC} / \mathrm{DC}$ converter to optimize the power of the PV generator.

The battery is usually connected to the $\mathrm{DC}$ bus through a DC/DC bidirectional converter. The $\mathrm{PI}$ and hysteresis regulators are generally the most used to regulate battery current. The current control strategy using hysteresis regulators is presented in (Seul-Ki Kim, 2008; Malla, 2014). Although this method is simple and robust, it generates high amplitude oscillations which can influence the quality of the power supply of the HRES. In (Bouharchouche, 2013; Rezvani, 2016), the authors introduced a linear PI regulator for current regulation. This type of regulator has a simple structure that is easy to implement in practice. But, it cannot guarantee stability and robustness against the variations of the parameters of the SEH and the rapid variations of the climatic conditions. 
The generation of harmonics, voltage and frequency fluctuations are the main electrical power quality problems (Khadem, 2010, Malla, 2013) that occur in the hybrid PV/wind/battery production system. Indeed, harmonics are mainly caused by the presence of non-linear devices such as power converters and non-linear loads (Linh, 2009). In addition, voltage and frequency fluctuations (Khadem, 2010, Ahmed, 2008) are caused in particular by variation in methodological conditions and disturbances in the network. One of the ways to overcome these problems is to design appropriate control laws for power converters in hybrid systems. Considerable technological advances in the field of power electronics have made it possible to implement high-performance control techniques in hybrid systems. The main challenge in this paper is to design new control strategies adapted to RES systems and in particular hybrid photovoltaic/wind /battery systems. For this reason, we have studied the control using SMC to find out what could be the contribution of this method applied to the control of our hybrid system. The SMC is a nonlinear type regulator that was first introduced for the control of variable design systems. Its fundamental advantages are the stability and robustness and vigour against external varieties of destabilizing influences parametric variation (Rezkallah, 2018, Benadli, 2015). These properties make this procedure suitable for controlling the frame of power converters in HRES. In literature, a few strategies are utilized to control the power converters (Benadli, 2015; Rezkallah, 2018), where the dynamic performances and the capacity of disturbance-rejection are effectively are viably improved. Ref (Benadli, 2015) a SMC and its application to VSC to improve grid-connected was evaluated and compared with the conventional PI controller. Ref (Rezkallah,2015) the real-time implementation of SMC has been compared with conventional $\mathrm{PI}$ in the application of a standalone inverter-based PV system.

This study develops a SMC for a HRES in grid-connected and autonomous modes of operation. Fig. 1 illustrates the PV/wind/battery hybrid system configuration of our study. The PV generator is coupled to the common DC bus via DC/DC boost converter. The latter is controlled by an MPPT algorithm to obtain the maximum power to guarantee the most extreme energy of the PV generator whatever the metrological conditions. On the one hand, the wind turbine converter line is equipped with a PMSG and a PWM rectifier. The last is controlled to adjust the operating point of the wind turbine to its optimum value. The battery interfaced by a bidirectional DC/DC converter can be charged or discharged depending on the production situation, the power demand and its state of charge to ensure the balance between production and consumption. The VSC serves as an interface between the DC bus and the AC bus. It can connect to the network or supply AC loads depending on the operating mode of the HRES.

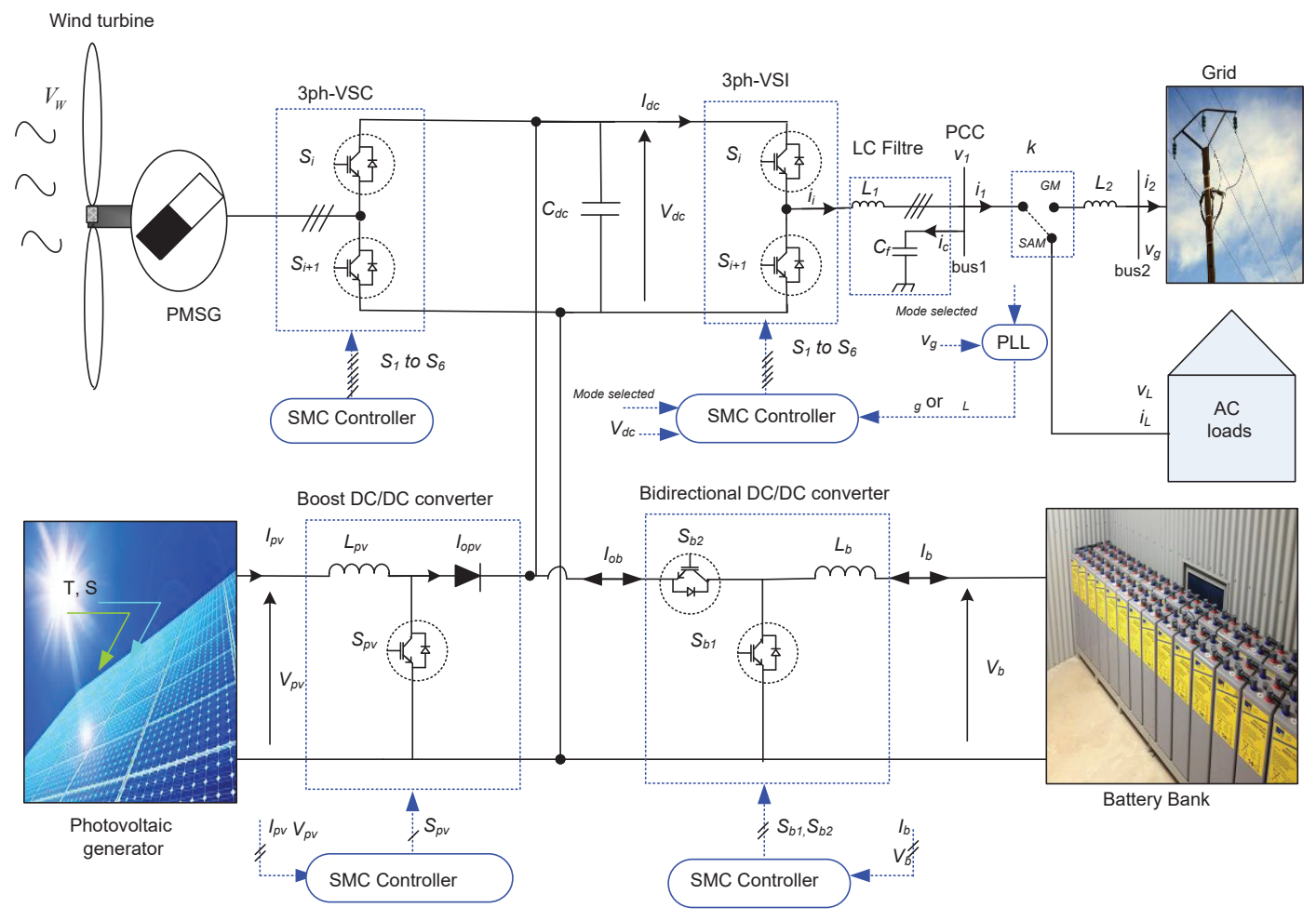

Fig. 1. The scheme of the proposed HRES 
The purpose of controlling the grid-connected VSC is to adjust the active and reactive power on the grid side, while keeping the DC bus voltage constant, and to inject very low THD current. However, in the SAM operation, the control of the VSC has for objectives to regulate the voltage and the frequency at the PCC bus ensuring the quality of the energy demanded by the load to provide current sinusoidal in phase with the mains voltage and having low total harmonic distortion (THD) (Benadli, 2020).

The main contributions and advantages of the proposed control scheme over other techniques used in the literature are as follows: the analysis of the control scheme SMC for PV/wind/battery in the two modes of operation: grid-connected and stand-alone, was attempted for the first time in this work; the developed SMC for VSC injects power into the network with good tracking indices and with a low THD which does not exceed the limit required by the standard value equal to $5 \%$ under grid fault; the proposed SMC control strategy has undeniable advantages in terms of voltage regulation and quality of current injected to the loads under different scenarios balanced load, unbalanced load and non-linear load. The developed SMC control strategies for the different power converters have ensured stable operation of the HRES under different operating conditions.

\section{Modeling of the hybrid system}

\subsection{Modeling of PV array}

In this work, the electrical model of a PV cell corresponds to a current generator in parallel with a diode. The current source represents generated photocurrent when the sunlight touches the solar panel, and the diode represents the transition zone P-N of the solar cell. The series resistance $\left(R_{s}\right)$ and the parallel resistance $\left(R_{s h}\right)$ represent the ohmic drops and the leakage currents. The output current is given by:

$$
I_{p v}=N_{p} I_{p h}-N_{p} I_{s}\left\{\exp \left[q\left(\frac{V_{p v}+R_{s} I_{p v}\left(N_{s} / N_{p}\right)}{N_{s} n K T}\right)-1\right]\right\}-N_{p} \frac{\left(V_{p v}+R_{s} I_{p v}\left(N_{s} / N_{p}\right)\right)}{R_{s h} N_{s}}
$$

where $I_{p h}$ is the photocurrent, Is is the cell's saturation current, $N_{p}$ and $N_{s}$ is the number of parallel and series strings, $V_{p v}$ is the PV system output voltage, $n$ is the ideality factor of the diode, $q$ is the electron charge $\left(q=1.6 .10^{-19}\right), K$ is the Boltzmann's constant $\left(K=1.38 .10^{-23}\right)$, and $T$ is the solar array panel temperature, $G$ is the solar irradiation level. To get the desired electrical power which is $9,3 \mathrm{~kW}$ peak power, we placed 8 modules connected in series $\left(N_{s m}=8\right)$ and 4 modules connected in parallel $\left(N_{p m}=4\right)$. The output power and the current of the PV array delivered by the PV source as a function of voltage for various irradiance levels are shown in Fig.2. In this figure, the impact of solar irradiation $(G)$ on the MPP and short circuit current $\left(I_{s c}\right)$ is well highlighted.

\subsection{Modeling of wind turbine}

The mechanical power extracts from the wind are expressed by:

$$
P_{m}=\frac{1}{2} \rho \pi r_{t}^{2} C_{p}(\lambda, \beta) v_{w}^{3}
$$

where $\rho$ is the air density, $r_{t}$ is the wind turbine rotor radius, $v_{w}$ is the wind speed and the power coefficient $C_{p}(\lambda, \beta)$. $C_{p}$ is called the power coefficient or the rotor efficiency and is a function of tip speed ratio $\lambda$ and pitch angle $\beta$.

The $C_{p}$ as a function of $\lambda$ and $\beta$ has been presented in Fig. 3. According to this figure, there is only one optimal point, denoted by $\lambda_{\text {opt, }}$, where $C_{p}$ is the maximum about 0.48 and the angle $\beta$ is set to zero. It is noted from the Fig. 3 that the value of $C_{p}$ can be changed by changing the pitch angle $(\beta)$.

Table 1. The parameters of SPR-305-WHT-U (305W) Solar Panel

\begin{tabular}{lc}
\hline Parameters & Values \\
\hline \hline Open circuit voltage $\left(V_{\text {oc }}\right)$ & $64.2 \mathrm{~V}$ \\
Voltage at $P_{\text {MPP }}\left(V_{\text {MPPT }}\right)$ & $54.7 \mathrm{~V}$ \\
Short circuit current $\left(I_{\text {sc }}\right)$ & $5.96 \mathrm{~A}$ \\
Number of cells in series $\left(n_{s}\right)$ & 96 \\
The MPP of PV module $\left(P_{\max }\right)$ & $305 \mathrm{~W}$ \\
\hline
\end{tabular}


The objective of the control is to follow the power curve between the minimum and nominal wind speed. For all wind speeds greater than the nominal wind speed, the power of the wind turbine must be maintained constant equals its nominal value by regulating the pitch angle $\beta$. This strategy is translated if only the speed ratio is maintained at its optimum value $\lambda_{\text {opt }}$ and the power coefficient is always at its maximum value $C_{p}=C_{p \max }$. The optimum rotational speed can be expressed as a function of wind speed as follows:

$$
\omega_{\text {mopt }}=\left(\lambda_{o p t} / r_{t}\right) v_{w}
$$

Considering that the conditions are optimal, and then Eq.(3) allows the calculation of the optimum power value:

$$
P_{m}=\frac{1}{2} \rho \pi r_{t}^{2} C_{p \max }\left(r_{t} / \lambda_{o p t}\right)^{2} \omega_{m o p t}
$$

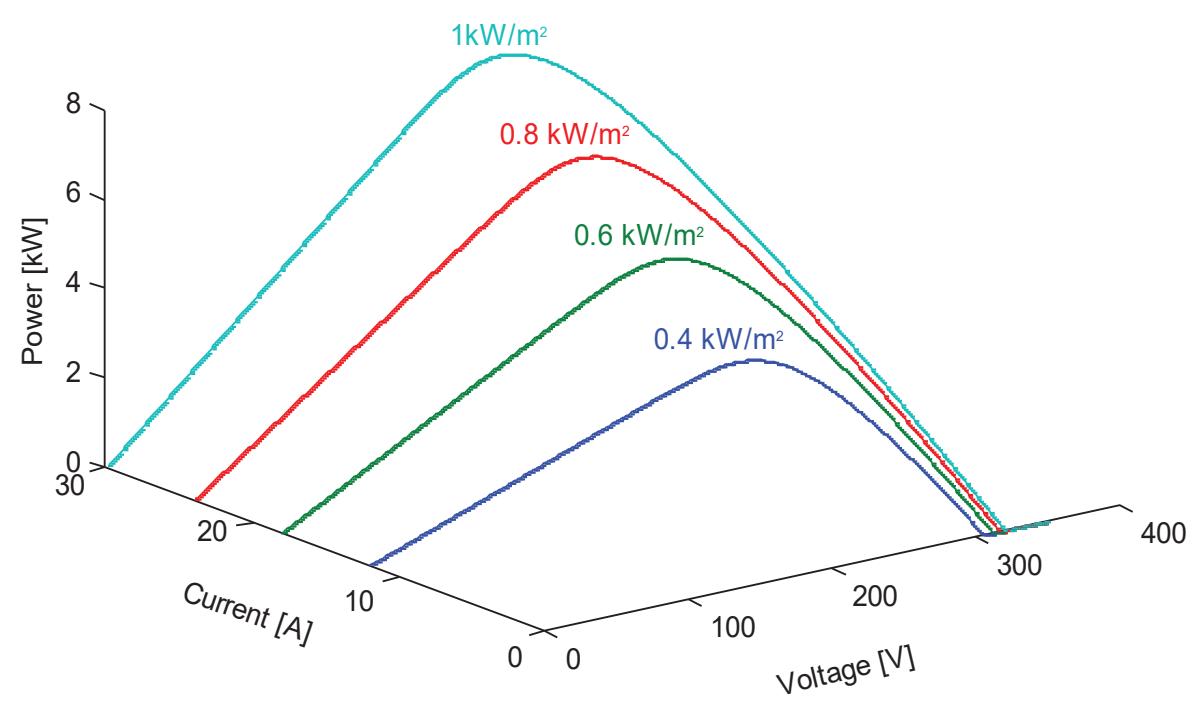

Fig. 2. $P-V-I$ output characteristics of the $P V$ array.

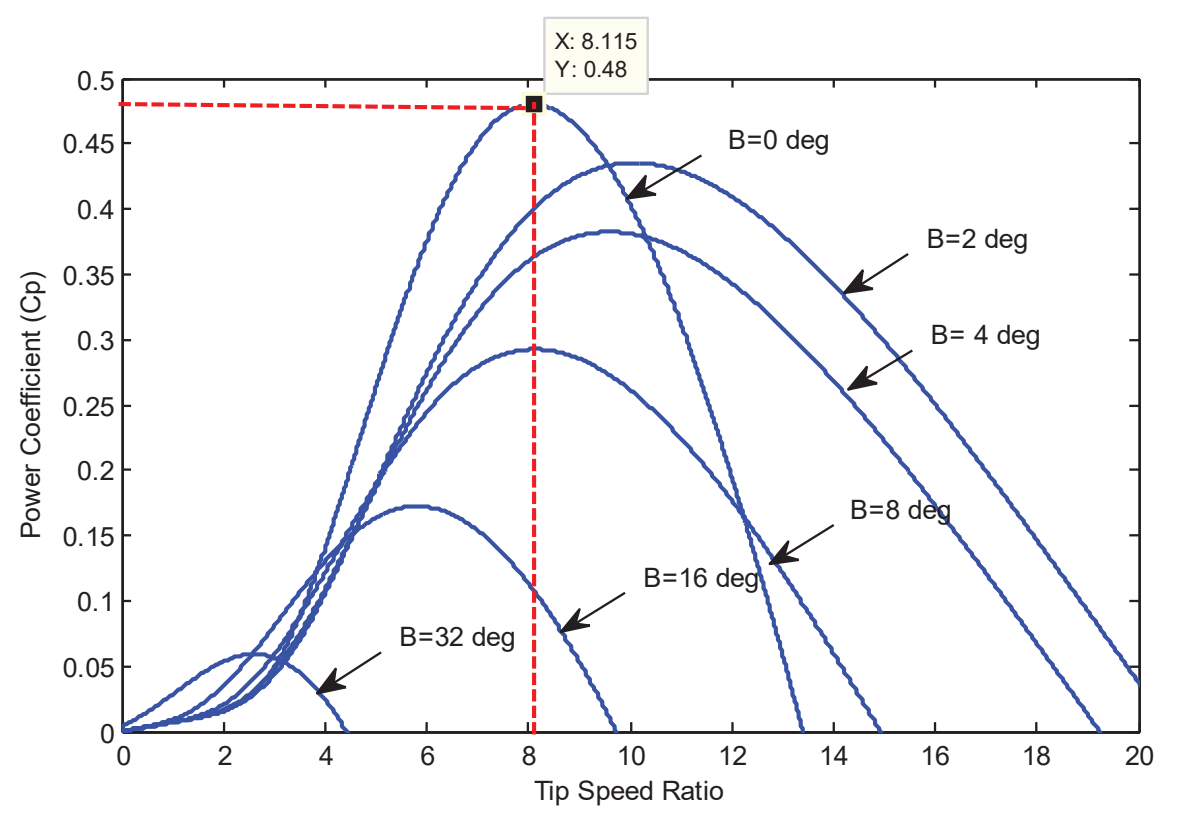

Fig. 3. Power coefficient for different values of $\beta$. 
It follows from Eq.(4), that the maximum mechanical power as a function of the rotational speed of the wind turbine only. Fig. 4 shows network wind power characteristics according to the rotational speed where the red curve represents the places of the optimum power, which corresponds to Eq.(4).

\subsection{PMSG modeling}

The electrical equations of PMSG in the $d-q$ reference frame are described by:

$$
\left\{\begin{array}{l}
\frac{d I_{s d}}{d t}=-\frac{R_{s}}{L_{s}} I_{s d}+\omega_{e} I_{s q}+\frac{1}{L_{s}} V_{s d} \\
\frac{d I_{s q}}{d t}=-\frac{R_{s}}{L_{s}} I_{s q}-\omega_{e} I_{s d}-\frac{1}{L_{s}} \omega_{e} \varphi+\frac{1}{L_{s}} V_{s d}
\end{array}\right.
$$

where $I_{s d}$ and $I_{s q}$ are the $d$-q components of stator currents, respectively; $V_{s d}$ and $V_{s q}$ are $d$ - $q$ components of the stator voltages, respectively; $R s$ and $L_{s}$ are the stator resistance and inductance, respectively; $\varphi$ is the flux linkage of the permanent magnet and $\omega_{e}$ is the electrical rotor speed of the PMSG.

The electromagnetic torque $\left(T_{e}\right)$ is given by:

$$
T_{e}=\frac{3}{2} n_{p} I_{s q}\left[\left(L_{s d}-L_{s q}\right) I_{s d}+\varphi\right]
$$

where $L_{s d}$, $L_{s q}$ are the two axes machine inductances, $n_{p}$ is the number of pole pairs.

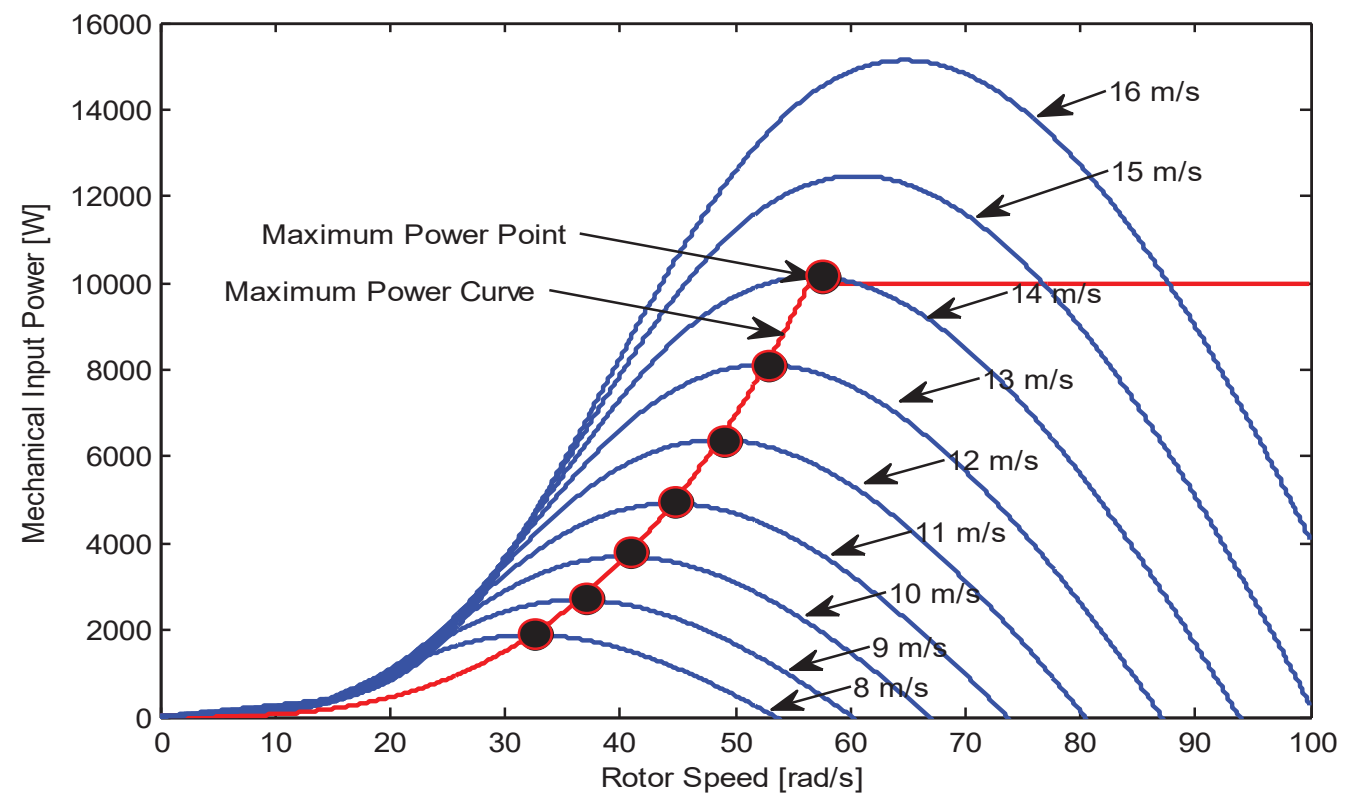

Fig. 4. Output power characteristic of the wind turbine for various wind speeds.

Table 2. Parameters of WT

\begin{tabular}{lc}
\hline Parameters & Values \\
\hline \hline Rated power $\left(P_{m-n}\right)$ & $10 \mathrm{~kW}$ \\
Rated speed $\left(v_{\text {w-n }}\right)$ & $12 \mathrm{~m} / \mathrm{s}$ \\
Area swept by blades $\left(r_{t}\right)$ & $2 \mathrm{~m}$ \\
Optimum tip speed ratio $\left(\lambda_{\text {opt }}\right)$ & 8.1 \\
\hline
\end{tabular}


In surface mounted PMSG $\left(L_{s d}=L_{s d}=L_{s}\right)$, the electromagnetic torque can be rewritten as follows:

$$
T_{e}=\frac{3}{2} n_{p} \varphi I_{s q}=K_{t} I_{s q}
$$

where $K_{t}$ is the torque constant. As is clear from Eq.(7), that the electromagnetic torque may be controlled directly the $q$-axis stator current.

The mechanical motion equation of the PMSG is described by:

$$
J \frac{d \omega_{m}}{d t}+B \omega_{m}=T_{m}-T_{e}
$$

where $J$ is the total mechanical inertia of the wind turbine and the PMSG, $B$ is the coefficient of viscous friction, $\omega_{m}$ is the mechanical rotor speed $\left(\omega_{m}=n_{p} \omega_{e}\right)$ and $T_{m}$ is the mechanical torque.

\subsection{Modeling of BESS}

The modelling of this battery is implemented in (Malla, 2014) and (Madaci, 2016). This model consists of a source voltage $E_{0}$ in series with a resistor $R_{b}$, where the voltage source is described by (Madaci, 2016).

$$
V_{b}=E-R_{b} I_{b}
$$

where $I_{b}$ and $E$ are respectively the battery current and the open-circuit voltage.

$$
E=E_{0}-K \frac{Q}{Q-\int I_{b} d t}+A \exp \left(-B \int I_{b} d t\right)
$$

where $E_{0}, K$ and $Q$ represent respectively the battery constant voltage, the polarization voltage and the battery capacity. Note that, $\int I_{b} \mathrm{dt}$ is the real battery charge, $A$ is the exponential zone amplitude and $B$ is the exponential zone time constant inverse.

\subsection{Model of VSC in SAM operation}

The diagram of a three-phase VSC with a LC filter in the SAM operation represented in Fig.1, the mathematical model of the VSC can be expressed as (Ridha, 2020):

$$
\left\{\begin{array}{l}
\frac{d v_{L}}{d t}=\frac{1}{C_{f}} i_{i}-\frac{1}{C_{f}} i_{L} \\
\frac{d i_{i}}{d t}=\frac{1}{L_{1}} v_{i}-\frac{1}{L_{1}} v_{L}
\end{array}\right.
$$

where $v_{i}=\left[v_{i a}, v_{i b}, v_{i c}\right]^{T}$ and $i_{i}=\left[i_{i a}, i_{i b}, i_{i c}\right]^{T}$ are respectively the vector output voltage and vector current of the VSC; $v_{L}$ $=\left[v_{L a}, v_{L b}, v_{L C}\right]^{T}$ and $i_{L}=\left[i_{L a}, i_{L b}, i_{L c}\right]^{T}$ are respectively the vector load voltage and load current; $L_{1}, C_{f}$ are respectively the inductance and capacitor of the LC filter.

Table 3. Parameters of PMSG

\begin{tabular}{ll}
\hline Parameters & Values \\
\hline \hline Rated power $\left(P_{m n}\right)$ & $10 \mathrm{~kW}$ \\
Number of poles pairs $\left(n_{p}\right)$ & 6 \\
Stator phase resistance $\left(R_{s}\right)$ & $0.00829 \Omega$ \\
Permanent magnet flux $(\phi)$ & $0.0171 \mathrm{~Wb}$ \\
Stator direct inductance $\left(L_{s d}\right)$ & $0.174 \mathrm{mH}$ \\
Stator quadrature inductance $\left(L_{s q}\right)$ & $0.174 \mathrm{mH}$ \\
Inertia of the whole system $(J)$ & $0.089 \mathrm{Kg} \cdot \mathrm{m}^{2}$ \\
Friction factor $(B)$ & $0.005 \mathrm{~N} \cdot \mathrm{m}$ \\
\hline
\end{tabular}


The Eq.(10) placed in the stationary abc can be transformed into the following equation in the synchronously rotating $d-q$ reference frame:

$$
\left\{\begin{array}{l}
\frac{d V_{L d}}{d t}=\omega V_{L q}-\frac{1}{C_{f}} I_{L d}+\frac{1}{C_{f}} I_{i d}+\Delta_{f_{m 1}} \\
\frac{d V_{L q}}{d t}=-\omega V_{L d}-\frac{1}{C_{f}} I_{L q}+\frac{1}{C_{f}} I_{i q}+\Delta_{f_{m 2}} \\
\frac{d I_{i d}}{d t}=-\frac{1}{L_{1}} V_{L d}+\omega I_{i q}+\frac{1}{L_{f}} V_{i d}+\Delta_{f_{m 3}} \\
\frac{d I_{i q}}{d t}=-\frac{1}{L_{1}} V_{L q}-\omega I_{i d}+\frac{1}{L_{f}} V_{i q}+\Delta_{f_{m 4}}
\end{array}\right.
$$

where $\omega$ is the angular frequency; $V_{L d}$ and $V_{L q}$ are the load $d-q$ axis voltage; and $I_{L d}$ and $I_{L q}$ is the load $d-q$ axis currents; $\Delta f_{m i}$ are bounded parametric uncertainties.

\subsection{Model of VSC in grid connected mode}

For the VSC associated with the network, the filters $L$ and LCL are utilized. In any case, the LCL filter has the favourable position over an $L$ filter of improving the performance of the indirect control of the current injected into the grid by effectively dimensioning the inactive components of this filter. The VSC state-space model with an LCL filter approach is depicted in (Dhar, 2016). Fig.1 depicts a schematic graph of a three-phase VSC with a LCL filter. The mathematical model of the VSC can be expressed in abc frame as:

$$
\left\{\begin{array}{l}
\frac{d i_{i, a b c}}{d t}=-\frac{R_{1}}{L_{1}} i_{i, a b c}+\frac{1}{L_{1}}\left(v_{i, a b c}-v_{1, a b c}\right)+\Delta_{f_{g 1}} \\
\frac{d i_{2, a b c}}{d t}=-\frac{R_{2}}{L_{2}} i_{2, a b c}+\frac{1}{L_{2}}\left(v_{c, a b c}-v_{2, a b c}\right)+\Delta_{f_{g 2}} \\
\frac{d v_{1, a b c}}{d t}=\frac{1}{C_{f}}\left(i_{i, a b c}-i_{1, a b c}\right)+\Delta_{f_{g 3}}
\end{array}\right.
$$

where $v_{1, a b c}$ is the voltage across filter capacitor (bus1) and $i_{1, a b c}$ is the current line passive $A C$ elements, $v_{2, a b c}$ is the voltage across bus 2 and $i_{1, a b c}$ is the current across bus $1 . \Delta f_{g i}$ are bounded parametric uncertainties.

The dynamic model of the grid connection in reference $d$-q frame with the grid bus 1 current $\left(i_{1, \text { abd }}\right)$ is obtained from Eq.(12) can be written as:

$$
\left\{\begin{array}{l}
\frac{d I_{i d}}{d t}=-\frac{R_{1}}{L_{1}} I_{i d}+\omega I_{i q}+\frac{1}{L_{1}}\left(V_{i d}-V_{1 d}\right)+\Delta_{f_{g 1}} \\
\frac{d I_{i q}}{d t}=-\frac{R_{1}}{L_{1}} I_{i q}-\omega I_{i d}+\frac{1}{L_{1}}\left(V_{i q}-V_{1 q}\right)+\Delta_{f_{g 2}}
\end{array}\right.
$$

The instantaneous power $S_{g 1}$ which is delivered to bus 1 is given as:

$$
S_{g 1}=P_{g 1}+j Q_{g 1}=\left|\left(V_{1 d} I_{i d}+V_{1 q} I_{i q}\right)+j\left(V_{1 q} I_{i d}-V_{1 d} I_{i q}\right)\right|
$$

In synchronous $d-q$ rotating frame, $V_{1 q}=0$. Therefore:

$$
S_{g 1}=P_{g 1}+j Q_{g}=\left|V_{1 d} I_{i d}-j V_{1 d} I_{i q}\right|
$$




\section{Control of the hybrid system}

\subsection{MPPT control PV system}

Fig.5 illustrates the principle of the APOAM method applied to the PV system through boost DC/DC converter. The objective of SMC is to force the PV voltage to follow their reference value given by the adaptive P\&O technique. This ensures optimal power extraction despite disturbances and climatic variations, using only the measurements of voltage and current of PV generator.

The flow chart of this method is illustrated in Fig. 6. The principle of this method may be given as follows:

$$
V_{p v}(k)=V_{p v}(k-1)+k_{p v} \operatorname{sign}(\Delta P)
$$

where

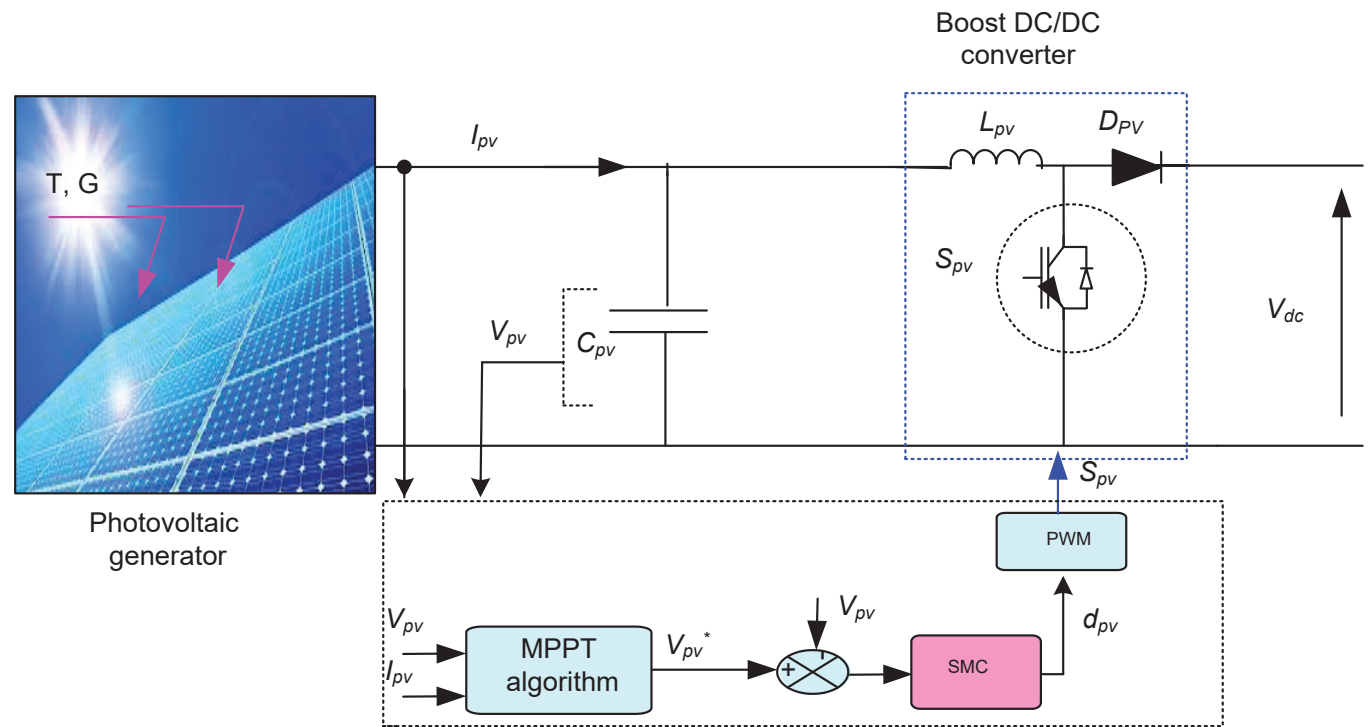

Fig. 5. Photovoltaic MPPT Control.

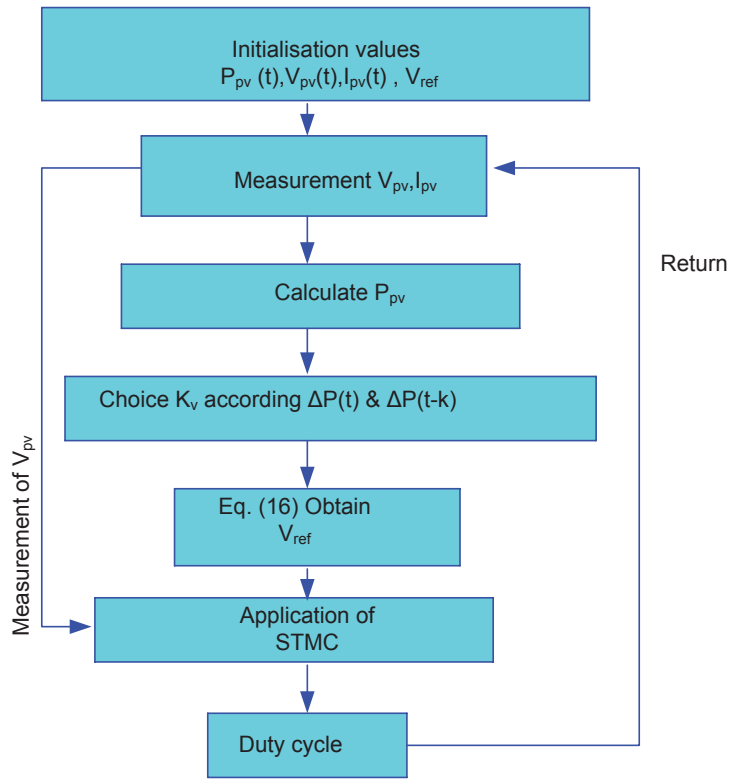

Fig. 6. Flow chart of the proposed APOAM. 


$$
\Delta P_{p v}=P(k)-P(k-1)
$$

where $k_{p v}$ is adaptive step gain which depends of state variation of the power.

The computation of a state model is necessary for the synthesis of this control law. This requires the characterization of the system by a mathematical equation reflecting the behavior of the PV boost DC/DC converter. The following equation is a mathematical representation of the relationship of the output of the PV and the input of the boost converter as follows (if $R_{s}=0, R_{s h}=\infty$ ):

$$
\dot{V}_{p v}=\frac{1}{C_{p v}}\left[I_{p v}=N_{p} I_{p h}-N_{p} I_{s}\left\{\exp \left[q\left(\frac{V_{p v}}{N_{s} n K T}\right)-1\right]\right\}\right]-\frac{I_{d c}}{C_{p v}} \cdot u
$$

The steps to design a SMC for a DC/DC converter can be found in (Tan, 2008) and (Wang, 2015). The following sliding surface as a linear combination of the state variables is described as:

$$
S=\alpha_{1} x_{1}+\alpha_{2} x_{2}+\alpha_{3} x_{3}
$$

where $\alpha_{1}, \alpha_{2}$, and $\alpha_{3}$ represent the control parameters of the SMC, usually referred to as sliding coefficients, and $x_{1}$, $x_{2}$, and $x_{3}$ denote the desired state feedback variables, which are defined as:

$$
\left\{\begin{array}{l}
x_{1}=V_{p v r e f}-V_{p v} \\
x_{2}=\frac{d\left(V_{p v r e f}-V_{p v}\right)}{d t} \\
x_{3}=\int\left(V_{p v r e f}-V_{p v}\right) d t
\end{array}\right.
$$

The control law of SMC for boost converter is of the form:

$$
u=\left\{\begin{array}{lll}
1 & \text { when } & S_{p v}>0 \\
0 & \text { when } & S_{p v}<0
\end{array}\right.
$$

In this paper, the SMC boost DC/DC converter operates at a constant switching frequency by employing PWM instead of Hysteresis-Modulation (Wang, 2015).

\subsection{Control of PMSG}

The control of the generator side using SMC is presented in the block diagram shown in Fig. 7. The MPPT was employed to provide the reference value of the $q$-axis stator current given by Eq.(7). Moreover, the reference of $d$-axis stator current is fixed to zero to achieve the unity power condition. The error between the measured current and its reference components is sent to the SMC. Finally, the output voltages $\left(V_{s d}{ }^{*}, V_{s q}{ }^{*}\right)$ are transformed to a- $\beta$ frame and will be an input of the Space Vector Modulation (SVM) to produce six switching signals $\left(S_{1}\right.$ to $\left.S_{6}\right)$ to the drive.

In this area, a SMC will be outlined, for the present control loops of Fig.1. Characterize the accompanying sliding surfaces:

$$
\left\{\begin{array}{l}
S_{s 1}=I_{s d r e f}-I_{s d} \\
S_{s 2}=I_{s q r e f}-I_{s q}
\end{array}\right.
$$

where $I_{\text {sdref, }} I_{\text {sqref }}$ are the reference variables for $I_{s d}, I_{s q}$, respectively. The control law is outlined forcing the sliding mode presence condition for surfaces $S_{s i} \dot{S}_{s i}<0$. 


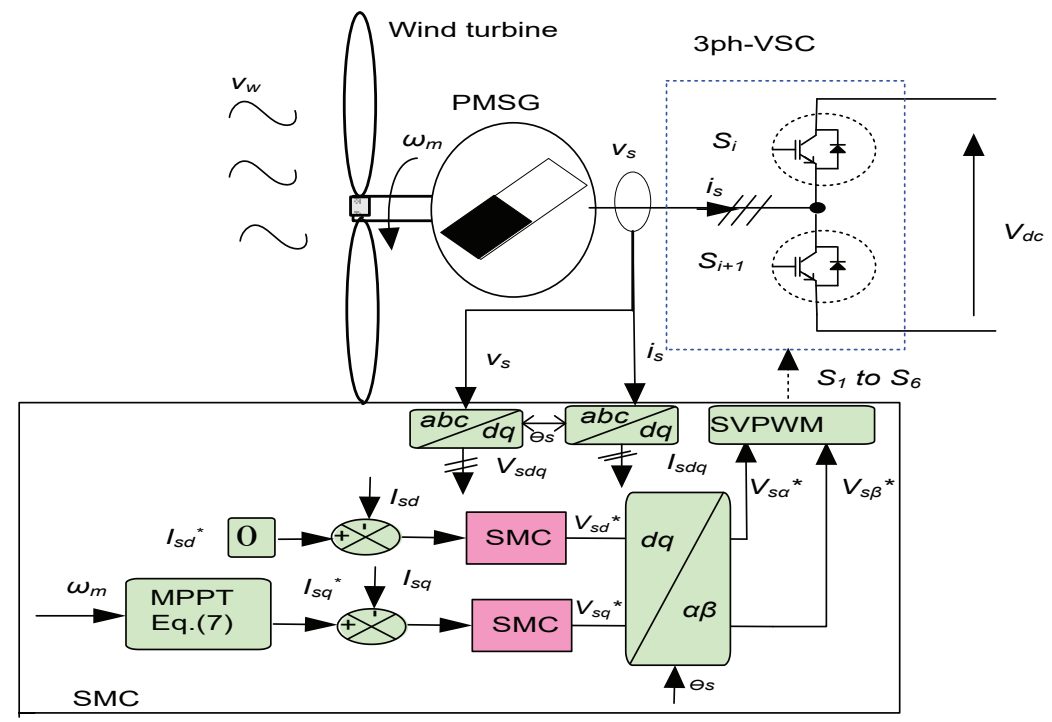

Fig. 7. Control of PMSG.

The control input is chosen to have the structure as follows:

$$
\left\{\begin{array}{l}
u_{s 1}=u_{e q s 1}+k_{s_{1}}\left|S_{s 1}\right|^{\alpha} \operatorname{sgn}\left(S_{s 1}\right) \\
u_{s 2}=u_{e q s 2}+k_{s_{2}}\left|S_{s 2}\right|^{\alpha} \operatorname{sgn}\left(S_{s 2}\right)
\end{array}\right.
$$

where $k_{s i}$ and $\alpha$ are positive constants. The parameters $k_{i}$ and $\alpha$ help to increase the switching speed when the state of the system moves away from the sliding surface. Therefore, we obtain a decrease in the chattering phenomenon, which decreases with increasing switching speed.

The equivalent control information is acquired from the invariance condition and given by the accompanying condition as $S_{s i}$ and $\dot{S}_{s i}=0 \Rightarrow u_{s i}=u_{\text {eqsi }}$ Condensing, the expression for the equivalent control terms $u_{\text {eqsi }}$ can be resolved as:

$$
\left\{\begin{array}{l}
u_{e q_{1}}=\left(R_{s} I_{s d}-\omega_{e} L_{q} I_{s q}\right)+L_{d} \dot{I}_{\text {sdref }} \\
u_{e q_{2}}=\left(R_{s} I_{s q}+\omega_{e} \frac{L_{d}}{L_{q}} I_{s d}+\omega_{e} \Psi\right)+\dot{I}_{s q r e f}
\end{array}\right.
$$

\subsection{BESS Control}

The block diagram of the proposed control of the bidirectional buck-boost DC/DC converter SMC controller is shown in Fig. 8. The sliding surface is defined for the regulation of the input current of the DC/DC buck-boost converter as follows:

$$
S_{b}=\sigma_{1} x_{1}+\sigma_{2} x_{2}+\sigma_{3} x_{3}
$$

where $\sigma_{1}, \sigma_{2}$, and $\sigma_{3}$ represent the control parameters of the SMC, usually referred to as sliding coefficients, and $x_{1}$, $x_{2}$, and $x_{3}$ denote the desired state feedback variables, which are defined as:

$$
\left\{\begin{array}{l}
x_{1}=I_{b r e f}-I_{b} \\
x_{2}=\frac{d\left(I_{b r e f}-I_{b}\right)}{d t} \\
x_{3}=\int\left(I_{b r e f}-I_{b}\right) d t
\end{array}\right.
$$




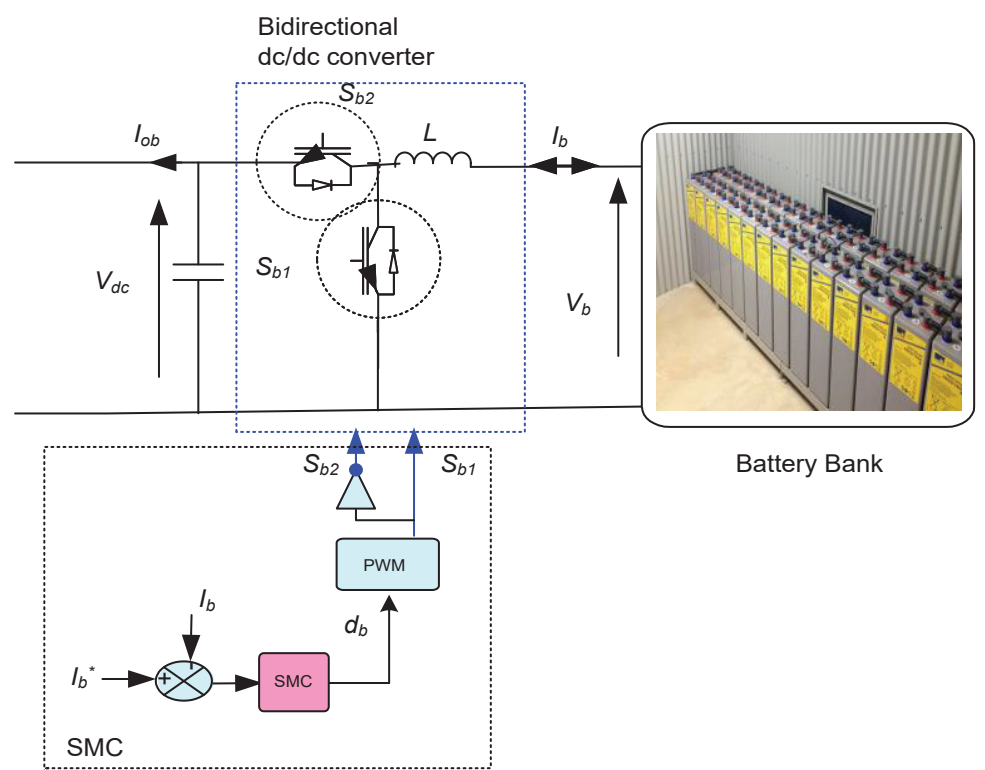

Fig. 8. Control of BESS.

The parameters $\sigma_{1}, \sigma_{2}$, and $\sigma_{3}$ are positive values determined by the resolution of the differential equation using the root locations to have the convergence appropriate the sliding surface to zero.

\subsection{Stand-alone control mode VSC}

The control diagram for a standalone VSC using the proposed SMC is presented in Fig. 9. The sliding surface of this control is defined as follows:

$$
\left\{\begin{array}{l}
s_{m 1}=V_{\text {Ldref }}-V_{L d} \\
s_{m 2}=V_{L q r e f}-V_{L q} \\
s_{m 3}=I_{\text {Ldref }}-I_{L d} \\
s_{m 4}=I_{\text {Lqref }}-I_{L q}
\end{array}\right.
$$

where $V_{\text {Ldref }}, V_{\text {Lqref }}, I_{\text {Ldref }}, I_{\text {Lqref }}$ are, respectively, the desired load current and voltage in $d$-and $q$-axes. The goal of the proposed control calculation that appeared in Fig. 9 is to direct the consistent load voltage and recurrence within the sight of different conditions. To accomplish these destinations, the accompanying conditions are forced:

$$
\left\{\begin{array}{l}
V_{\text {Ldref }}=V_{L L} \\
V_{\text {Lqref }}=0 \\
\theta=\omega t=2 \pi f
\end{array}\right.
$$

where $V_{L L}$ is the line-line load voltage and $f$ is the load frequency.

The control input is defined as follows:

$$
\left\{\begin{array}{l}
u_{m 1}=u_{e q m 1}+k_{m 1}\left|s_{v_{L d}}\right|^{\alpha} \operatorname{sgn}\left(s_{m 1}\right) \\
u_{m 2}=u_{e q m 2}+k_{m_{2}}\left|s_{v_{L q}}\right|^{\alpha} \operatorname{sgn}\left(s_{m 2}\right) \\
u_{m 3}=u_{e q m 3}+k_{m_{3}}\left|s_{m_{3}}\right|^{\alpha} \operatorname{sgn}\left(s_{m_{3}}\right) \\
u_{m 4}=u_{e q m 4}+k_{m_{4}}\left|s_{m_{4}}\right|^{\alpha} \operatorname{sgn}\left(s_{m_{4}}\right)
\end{array}\right.
$$

where $k_{m i}$ is a positive gain. 


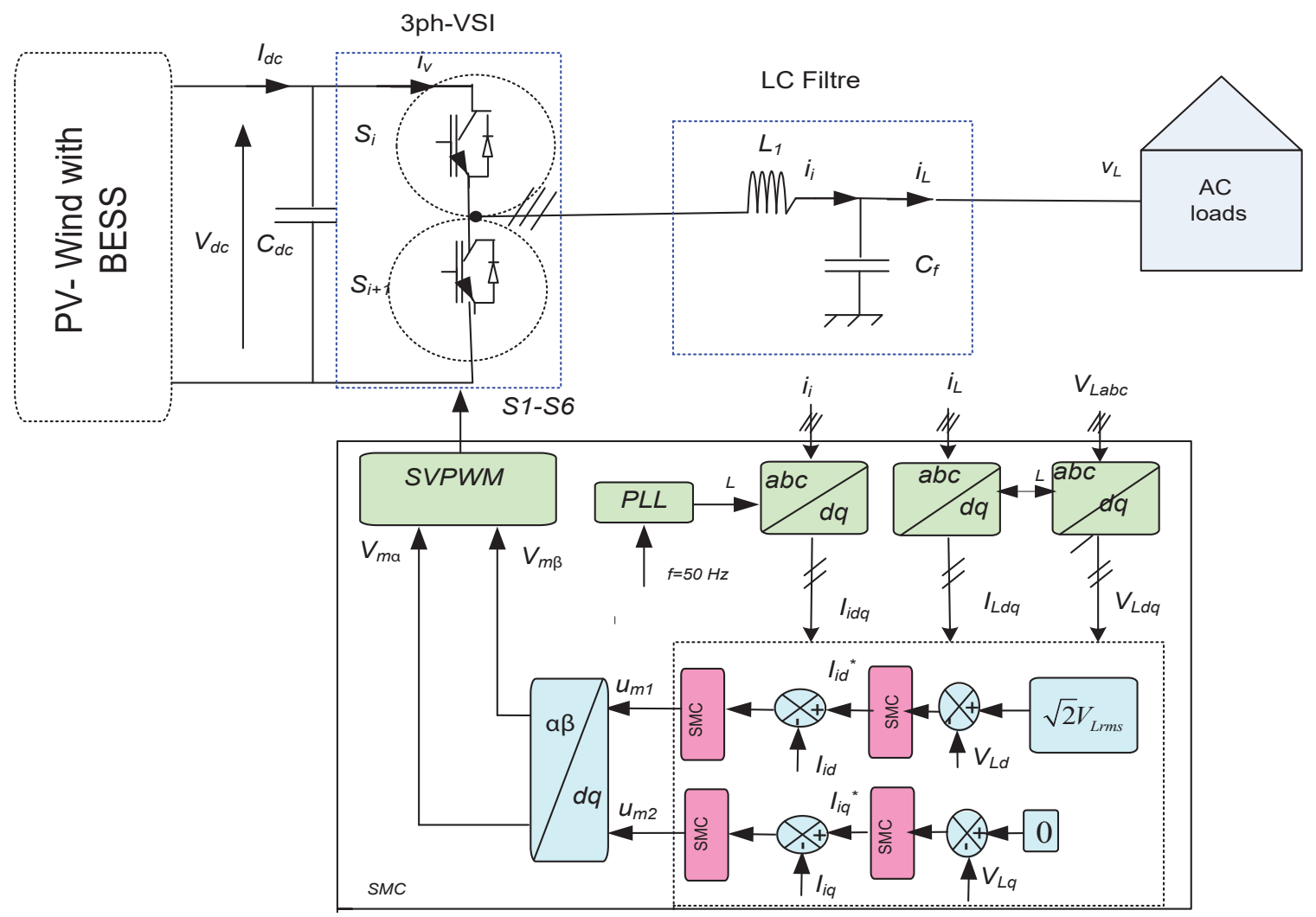

Fig. 9. Control VSC for stand-alone mode.

The equivalent control input is obtained from the invariance condition and given by the accompanying condition as $S_{m i}$ and $\dot{S}_{m i}=0 \Rightarrow u_{m i}=u_{\text {eqmi }}$ Therefore, the expression for the equivalent control terms $u_{\text {eqmi }}$ can be obtained as:

$$
\left\{\begin{array}{l}
u_{\text {eqm } 1}=C_{f} \omega V_{L q}+I_{L d} \\
u_{\text {eqm } 2}=-C_{f} \omega v_{L d}+I_{L q} \\
u_{\text {eqm } 3}=V_{L d}+L_{f} I_{L d}-\omega L_{f} I_{L q} \\
u_{e q m 4}=V_{L q}+L_{f} I_{L q}+\omega L_{f} I_{L d}
\end{array}\right.
$$

The objective of the SMC is to guarantee the convergence of the operation points to predetermine sliding boundaries. To verify the stability of the system, Lyapunov function candidates are used. At that point, the range of $k_{m i}$ can be determined as follows: are positive gains chosen in such a way as to respect the condition of the convergence of the SMC.

$$
\left\{\begin{array}{l}
k_{m 1}>C_{f}\left|\Delta_{f_{1}}\right| ; k_{m 2}>C_{f}\left|\Delta_{f_{2}}\right| \\
k_{m 3}>L_{f}\left|\Delta_{f 3}\right| ; k_{m 4}>L_{f}\left|\Delta_{f 4}\right|
\end{array}\right.
$$

\subsection{Grid connected control mode VSC}

Fig. 10 demonstrates a block diagram of the proposed control of VSC associated with the grid framework utilizing a sliding mode current controller. The components of the grid side current are compared with its references. The errors between them go through the two controllers sliding mode. The outputs of the two controllers give the components of the voltage of the SVPWM in the reference $\alpha-\beta$ through the inverse transformation of Park. 


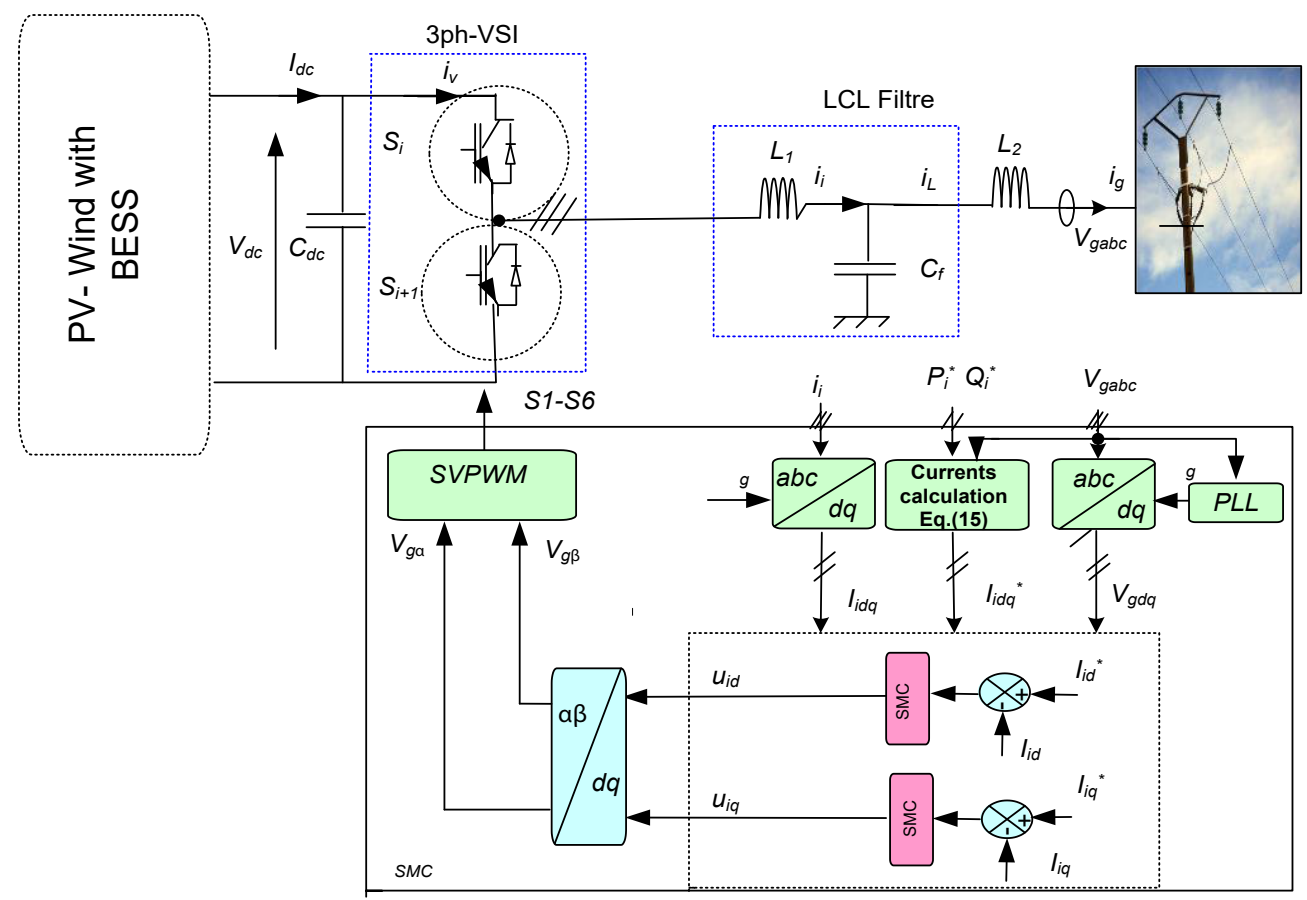

Fig. 10. Control VSC for grid-connected mode.

The $I_{\text {idref }} I_{\text {iqref }}$ currents references are linked to the desirable active and reactive grid powers is obtained as follows:

$$
\left\{\begin{array}{l}
I_{\text {idref }}=P_{1 \text { ref }} / V_{i d g} \\
I_{\text {iqref }}=Q_{\text {ref }} / V_{i d g}
\end{array}\right.
$$

The proposed sliding surface is defined as follows:

$$
\left\{\begin{array}{l}
S_{i_{i d}}=I_{\text {idref }}-I_{i d} \\
S_{i_{i q}}=I_{\text {iqref }}-I_{i_{q}}
\end{array}\right.
$$

The control input is chosen to have the structure as follows:

$$
\left\{\begin{array}{l}
u_{i d}=u_{\text {eqg } 1}+k_{g 1}\left|S_{i d}\right|^{\alpha} \operatorname{sgn}\left(S_{i d}\right) \\
u_{i q}=u_{e q g}+k_{g 2}\left|S_{i q}\right|^{\alpha} \operatorname{sgn}\left(S_{i q}\right)
\end{array}\right.
$$

The expression for the equivalent control terms $u_{\text {eqi }}$ can be determined as:

$$
\left\{\begin{array}{l}
u_{\text {eqg1 }}=R_{1} I_{i d}-L_{1} \omega I_{i q}+V_{1 d} \\
u_{\text {eqg } 2}=R_{1} I_{i q}+L_{1} \omega I_{i d}+V_{1 q}
\end{array}\right.
$$

The ranges of the switching gains are given as:

$$
\left\{\begin{array}{l}
k_{g 1}>L_{1}\left|\Delta_{f_{g 1}}\right| \\
k_{g 2}>L_{1}\left|\Delta_{f_{g 2}}\right|
\end{array}\right.
$$

It remains only to choose sufficiently large gain values to check the convergence of $S_{s i}$ to zero. 


\section{Results and discussion}

Different simulations results are used to analyze the dynamic performance HRES both GCM and SAM are represented in this work. The overall configuration is shown in Fig. 1 of HRES were simulated by utilizing the Simulink/ Matlab. The DC-link voltage is controlled at $700 \mathrm{~V}$. The grid voltage AC load is $230 \mathrm{~V} / 50 \mathrm{~Hz}$. The distribution powers of the HRES with the variable input source. Specifically, the wind speed increases from $10 \mathrm{~m} / \mathrm{s}$ to $14 \mathrm{~m} / \mathrm{s}$ at $t=0.3 \mathrm{~s}$, respectively. The solar irradiation increased from $0.6 \mathrm{~kW} / \mathrm{m}^{2}$ to $1 \mathrm{~kW} / \mathrm{m}^{2}$ at $t=0.2 \mathrm{~s}$ and decreased from $1 \mathrm{~kW} /$ $\mathrm{m}^{2}$ to $0.8 \mathrm{~kW} / \mathrm{m}^{2}$ at $t=0.4 \mathrm{~s}$ respectively, while the temperature is constant, equal to $25^{\circ} \mathrm{C}$.

The SMC must be robust against uncertain parameters. For this reason, the uncertainties are formalized and included in the model. The values of parametric variations $\left(R_{s}, L_{s}, R_{1}, L_{1}, L_{f}, C_{f}\right)$ are $5 \%$ of its nominal value. The convergence condition of SMC only gives the range of $k_{m i}$; their values are adjusted by simulation taking into account uncertain parameters and the following performance criteria: speed of response without significant overshoot, reduction of the amplitude of oscillations; reduction of static error.

\subsection{Isolated operation with variable input source and load condition (off-grid)}

Simulations are executed to illustrate the performance of the proposed HRES controller under following different cases: case 1) Linear load is connected to the system at $t=0 \mathrm{~s}$ and is disconnected at $t=0.3 \mathrm{~s}$; case 2 ) nonlinear load (three-phase diode rectifier, $L_{\text {load }}=10 \mathrm{mH}, R_{\text {load }}=50 \Omega$ ) is connected to system at period $t \in[0.20 .3] \mathrm{s}$; case 3) Increased of resistive load by $100 \%$ at period $t \in\left[\begin{array}{ll}0.30 .4\end{array}\right]$; case 4$)$ unbalanced resistive load $\left(R_{L b}=87.5 \% R_{L a}\right.$ $R_{L c}=75 \% R_{L a}$ ) at period $t \in[0.40 .5]$. Fig. 11 shows the control performance of PV system with solar irradiance variations whose data sets. It is seen from this figure the PV system controller tracks the MPPs of solar energy regardless of the rapidly changing wind speed and load condition. The comparison between the APOAM and $\mathrm{P} \& O$ algorithms of power response is illustrated in Fig.12. It is clear from this figure that the proposed algorithm is effective in changing weather conditions because the work point of the system oscillates weakly around the maximum power point.

Fig.13 shows the response of the wind turbine system in SAM operation. The wind speed $v_{w}$, the power coefficient, the measured and reference rotor speed of PMSG, the reference and output of torque of the wind turbine, the wind turbine output power are shown from Fig.13. The simulation results demonstrate that the proposed controller operates the wind generator in the maximum power point regardless of various environmental conditions and load types in this tested.
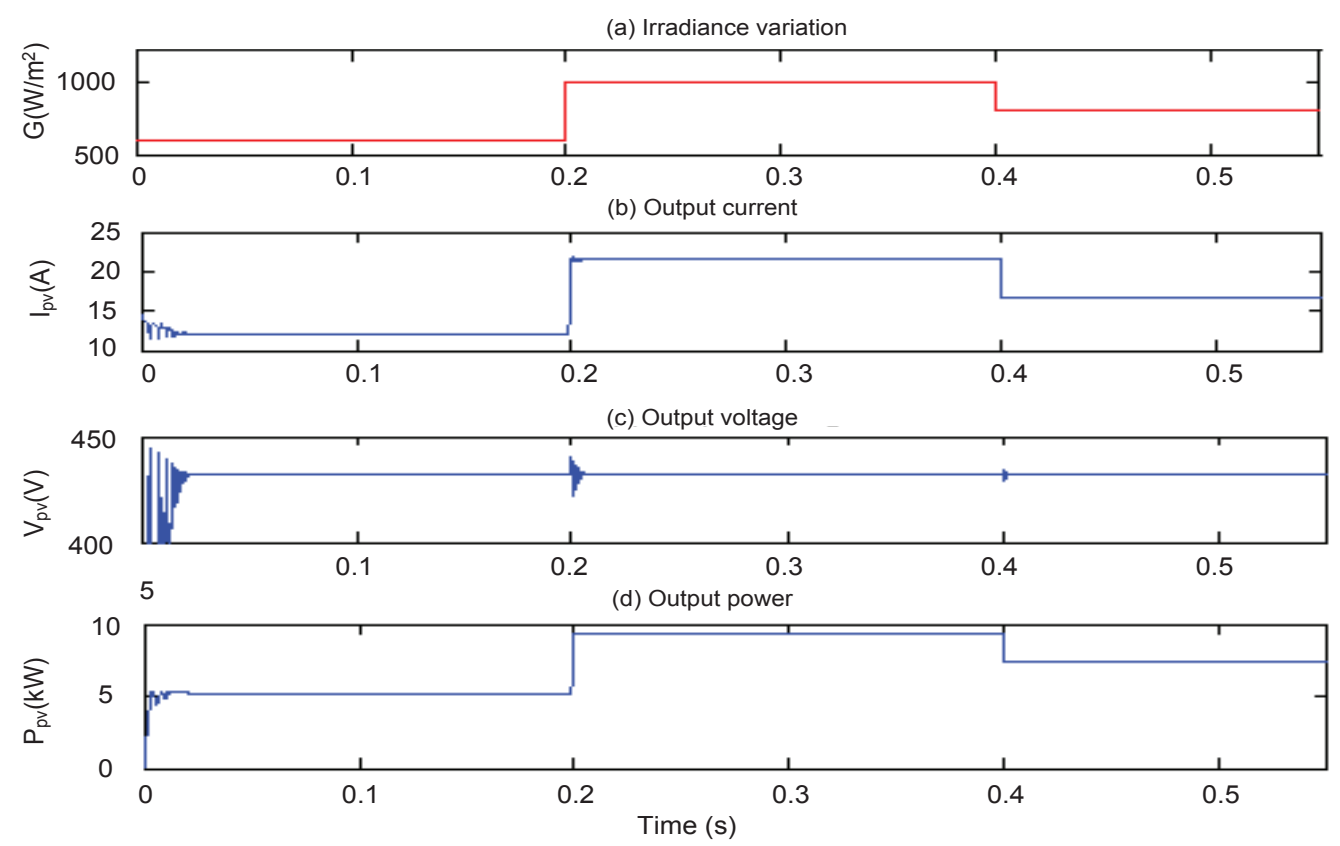

Fig. 11. Control performance $P V$ system in SAM operation. 
Fig. 14 shows the response of the BESS system in SAM operation. This figure shows battery voltage $\left(V_{b}\right)$, state of charge of the battery (SOC\%), battery current $\left(I_{b}\right)$, the output of power of the battery. It is observed, at period $t \in[00.2]$ the aggregate of wind and PV produced power is not adequate to supply the heap request to supply the load demand. Under this circumstance, the battery release with a positive current. At period $t \in\left[\begin{array}{ll}0 & 0.2\end{array}\right]$ the power request

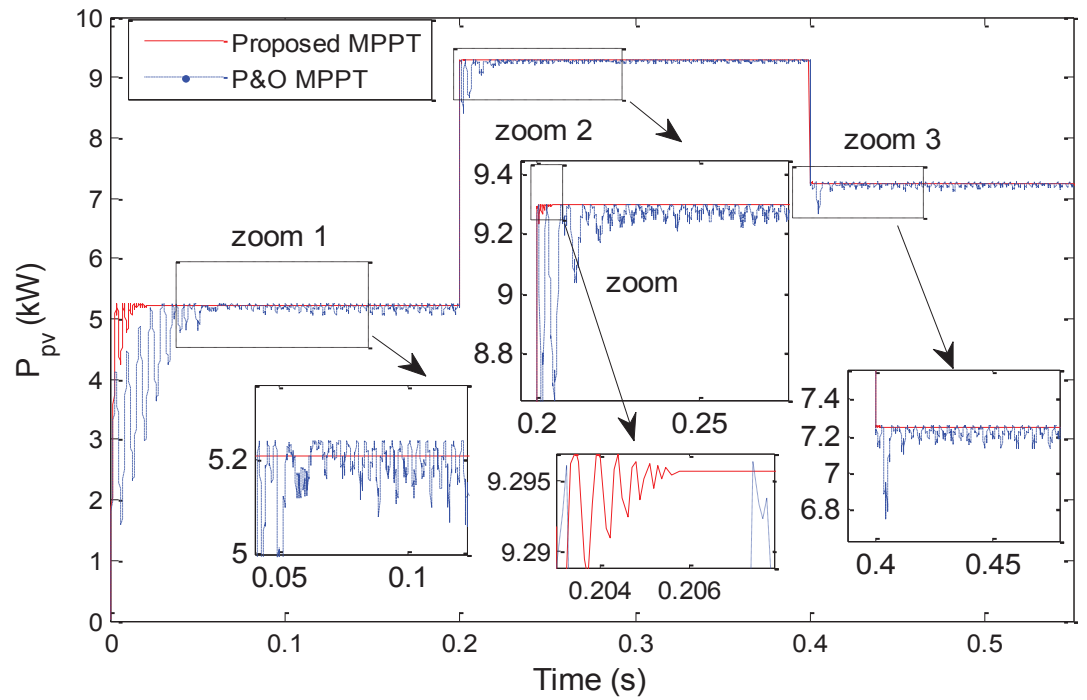

Fig. 12. Comparison of power response between $A P O A M$ and $P \& O$ algorithms.

(a) Wind speed

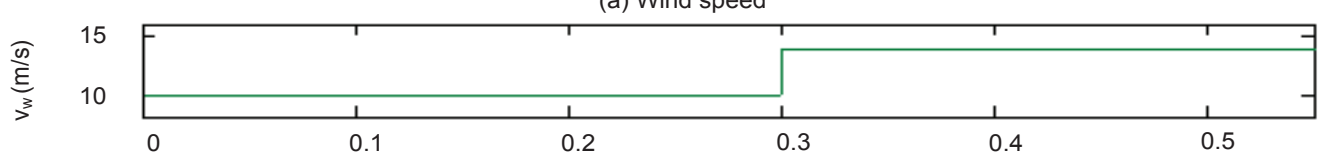

(b) Power coefficient
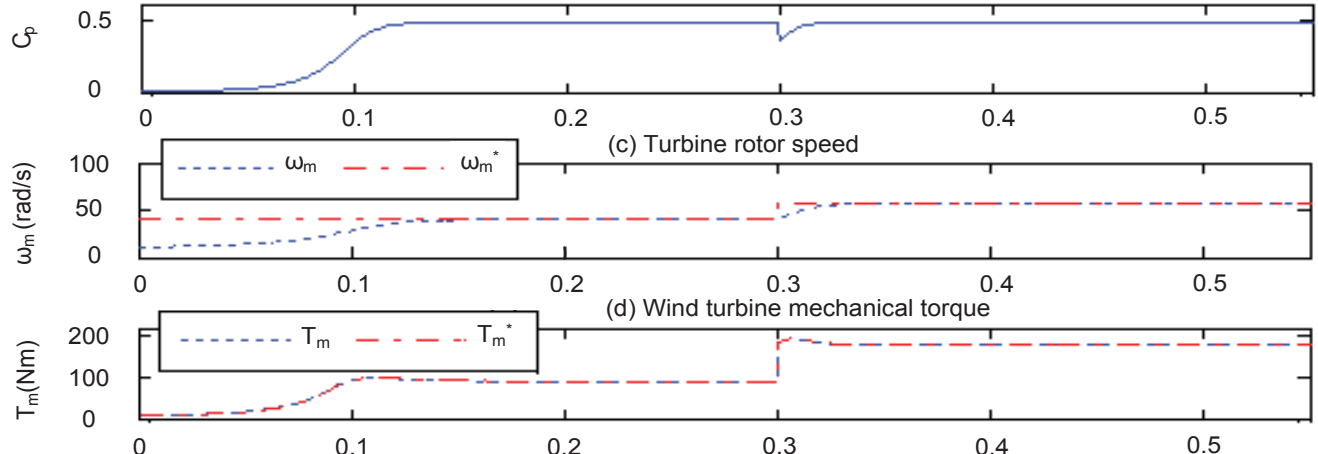

(e) d-axis and q-axis stator currents

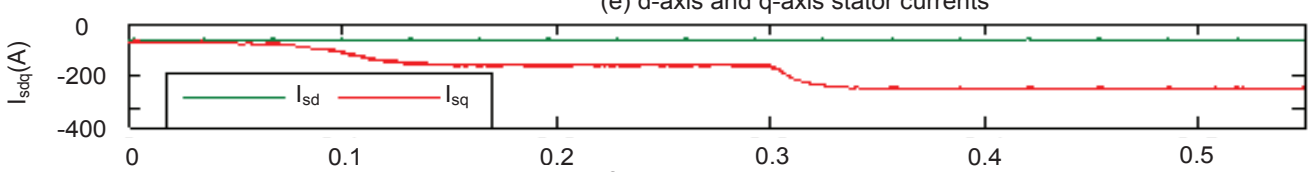

(f) Wind turbine powe

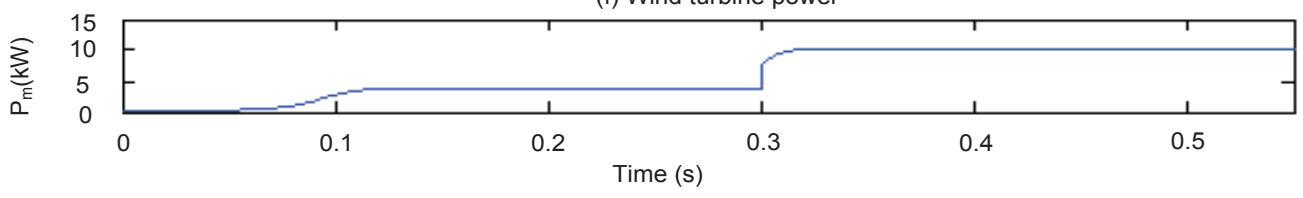

Fig. 13. Control performance Wind turbine system in SAM operation. 
by the load is not as much as the power created by the sources. In this way, the battery is accused of a negative current. The reference and measured DC current as appeared in Fig.14 (b). It is observed that the measured battery current follows the reference current to supply load demand by charging or discharging this storage.

Fig.15 show the simulation results of the proposed control technique under in this test, respectively of load voltages $\left(v_{L, a b c}, V_{L d q}\right)$, load currents $\left(i_{L, a b c}, I_{L d q}\right)$, output currents of VSC $\left(i_{i, a b c}, I_{i d q}\right)$, the dc bus voltage and active power of the load. The VSC can regulate the voltage level of local AC load at $230 \mathrm{~V}$ and the frequency at $50 \mathrm{~Hz}$ as shown
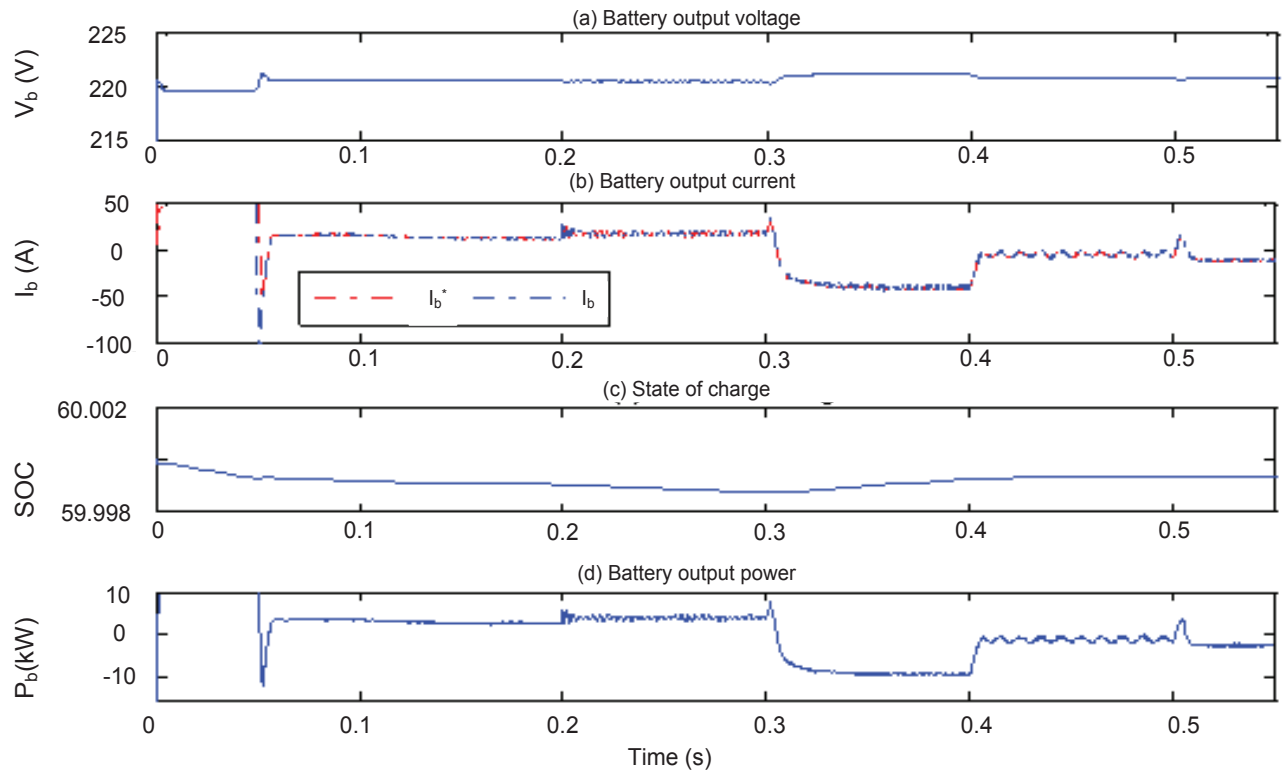

Fig. 14. Control performance of the BESS in SAM operation.
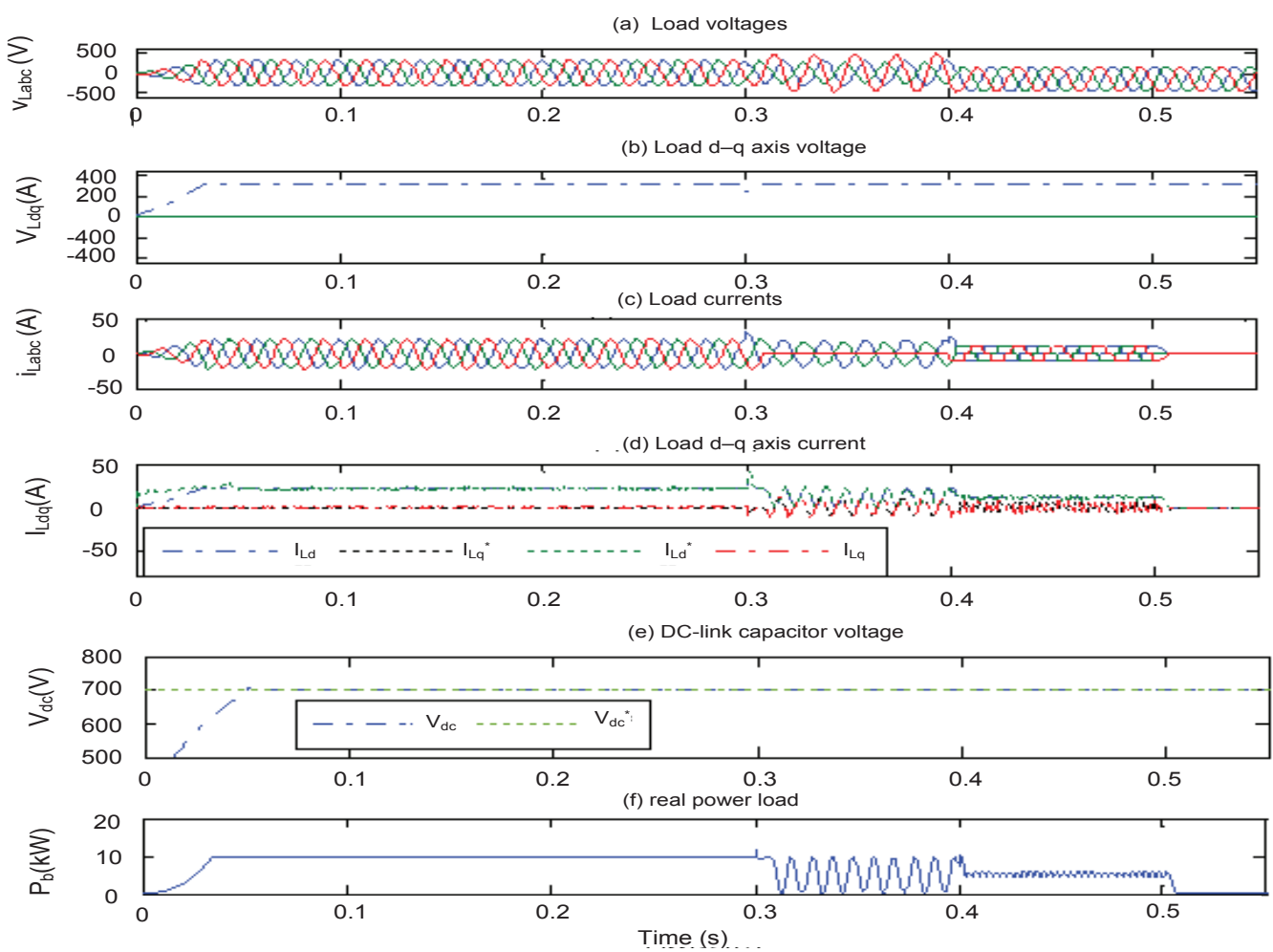

Fig. 15. Control performance VSC in SAM operation. 
in Fig.15. It can be observed from the simulation results that the proposed SMC based control strategy affirms the fast dynamic response and voltage tracking performance (small steady-state error and lower part) under different load types (balanced load, unbalanced load, and nonlinear load).

To better appreciate the upsides of the proposed approach, we propose a progression of comparable tests with the traditional PI controller as appeared in Fig.16. It can be seen from this figure and Table 4 that the proposed control system has more points of interest in wording in terms of voltage regulation, fast steady-state error, and low harmonic distortion).

\subsection{Grid connected operation with variable input source and grid fault}

Simulations are executed to delineate the execution of the proposed HRES controller when wind speed and solar irradiance change and under following different cases of grid fault which; disconnecting of the phase $A$ at period $t \in[0.20 .22]$, disconnecting of two phases $A$ and $B$ at period $t \in[0.30 .32]$, disconnecting of three phases at period $t \in[0.40 .42]$. Fig. 17 shows the control performance of PV system with solar irradiance variations whose data sets. It is seen from this figure the PV framework controller could produce the most extreme power regardless of the rapidly changing wind speed and grid fault.

Fig.18 shows the response of the wind turbine system in GCM operation. We observe, therefore, an almost perfect tracking of the operating point imposed by the MPPT algorithm under different environmental conditions and grid fault in this study.

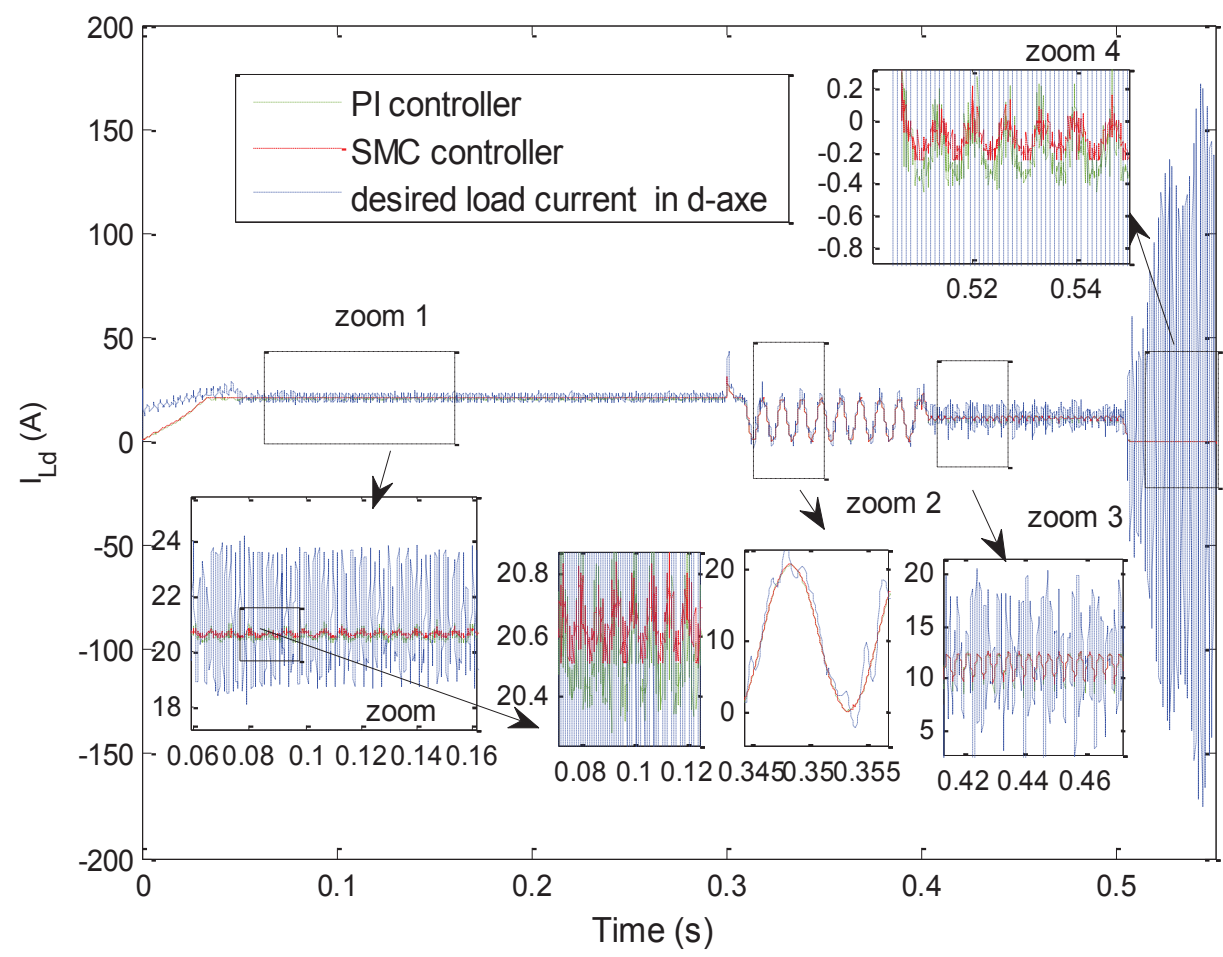

Fig. 16. Performance of direct voltage control in SAM (PI control, SMC).

Table 4. Summary of results in SAM

\begin{tabular}{llcc}
\hline Cases & Parameters & Pl controller & SMC controller \\
\hline \hline 1 & $T H D_{i}(0-0.2 \mathrm{~s}),\left(V_{\text {Labc }}\right)$ & $3.73 \%,(220,220,4,220,1)$ & $0.04 \%,(220,220,220)$ \\
2 & $T H D_{i}(0.2-0.3 \mathrm{~s}),\left(V_{\text {Labc }}\right)$ & $10,6 \%,(220,8220,8,220,8)$ & $10,51 \%,(220219,9219,9)$ \\
3 & $T H D_{i}(0.3-0.4 \mathrm{~s}),\left(V_{\text {Labc }}\right)$ & $4.74 \%,(220,2220,3,220,3)$ & $1.2 \%,(220220220.1)$ \\
4 & $T H D_{i}(0.4-0.5 \mathrm{~s}),\left(V_{\text {Labc }}\right)$ & $3.91 \%,(233,4,224,7,203,8)$ & $3.1 \%,(233.1224,2203.1)$ \\
\hline
\end{tabular}


(a) Irradiance variation

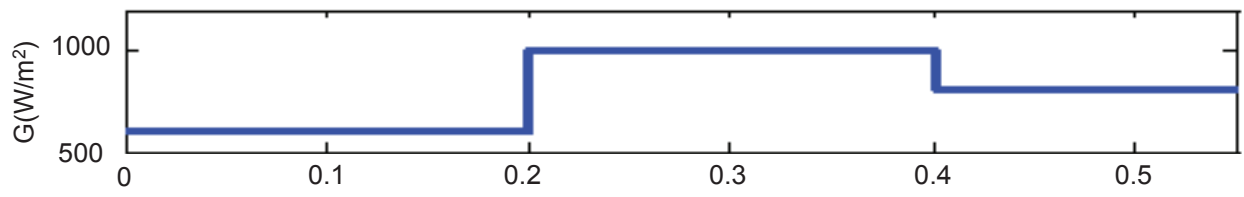

(b) Output current

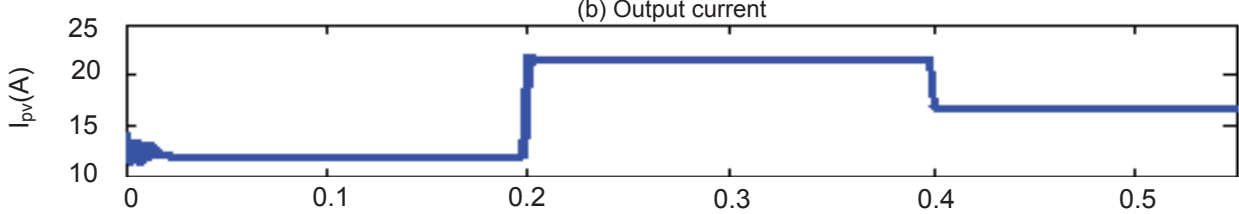

(c) Output voltage

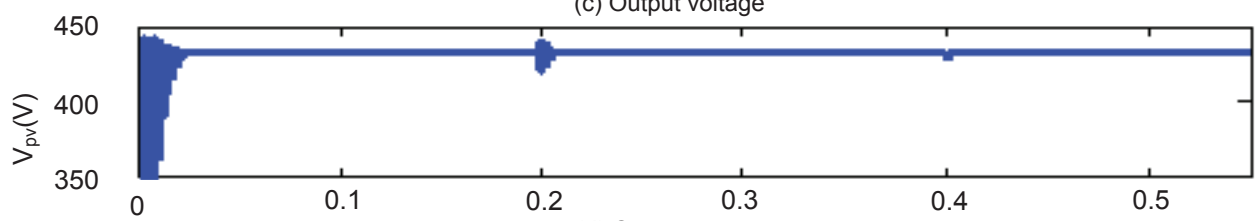

(d) Output power

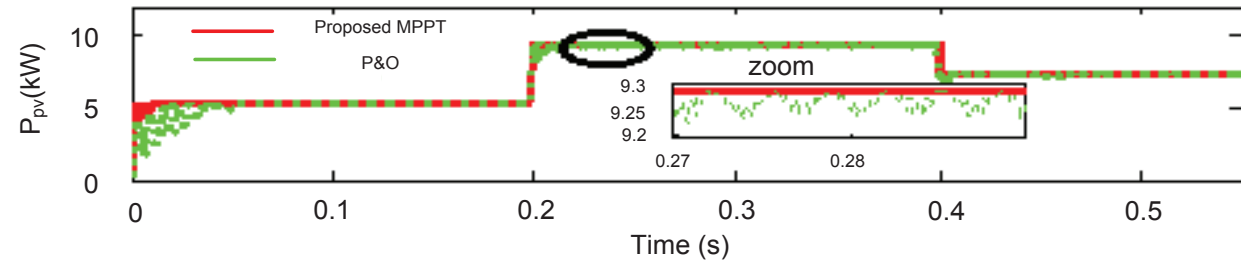

Fig. 17. Control performance PV system in GCM operation.

(a) Wind speed

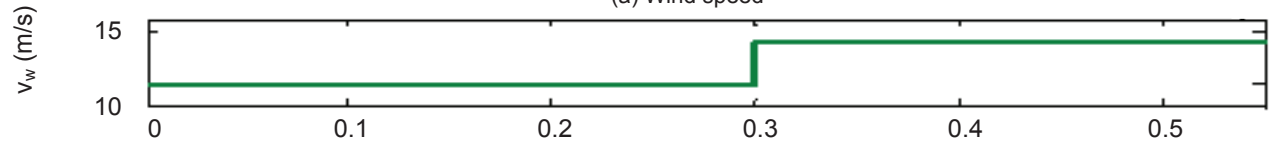

(b) Power coefficient
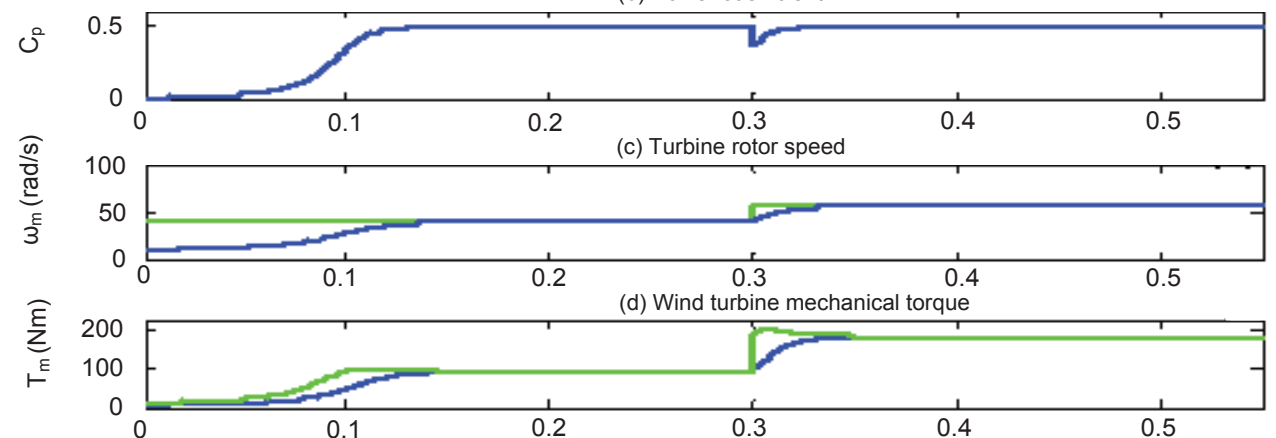

(e) d-axis and q-axis stator current
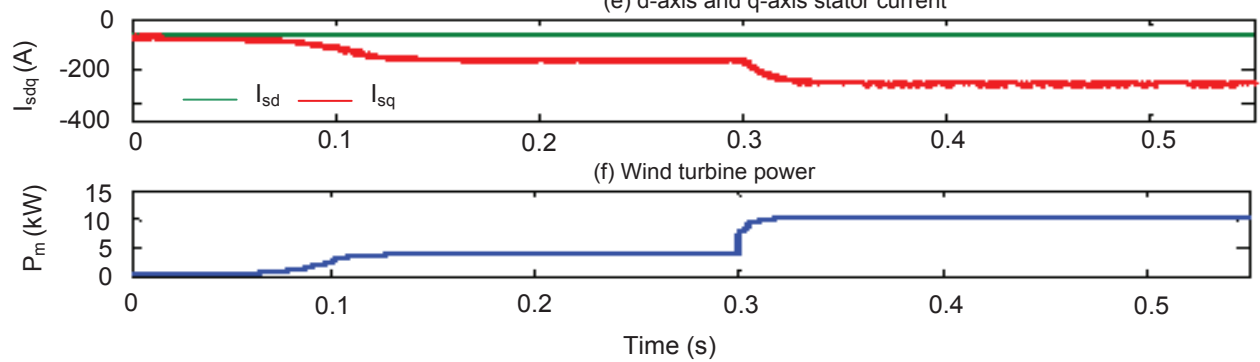

Fig. 18. Control performance Wind turbine system in GCM operation. 
Fig.19 shows the response of the BESS system in GCM operation. This figure shows battery voltage $\left(V_{b}\right)$, state of charge of the battery (SOC\%), battery current $\left(I_{\mathrm{b}}\right)$, the output of power the battery. It is observed that the battery charged with a negative power with good current control of this storage.
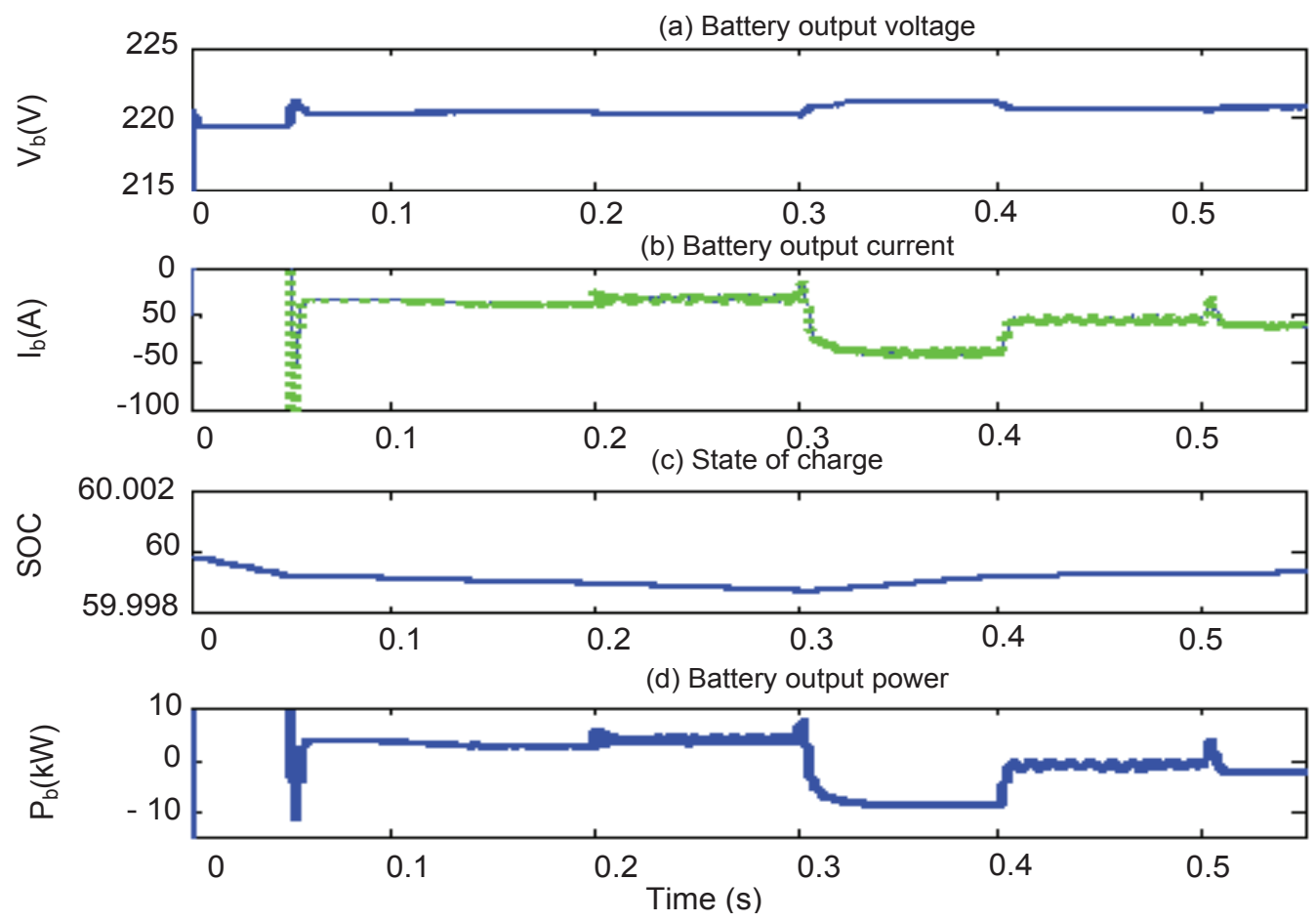

Fig. 19. Control performance of the BESS in GCM operation.

(a) Grid voltages
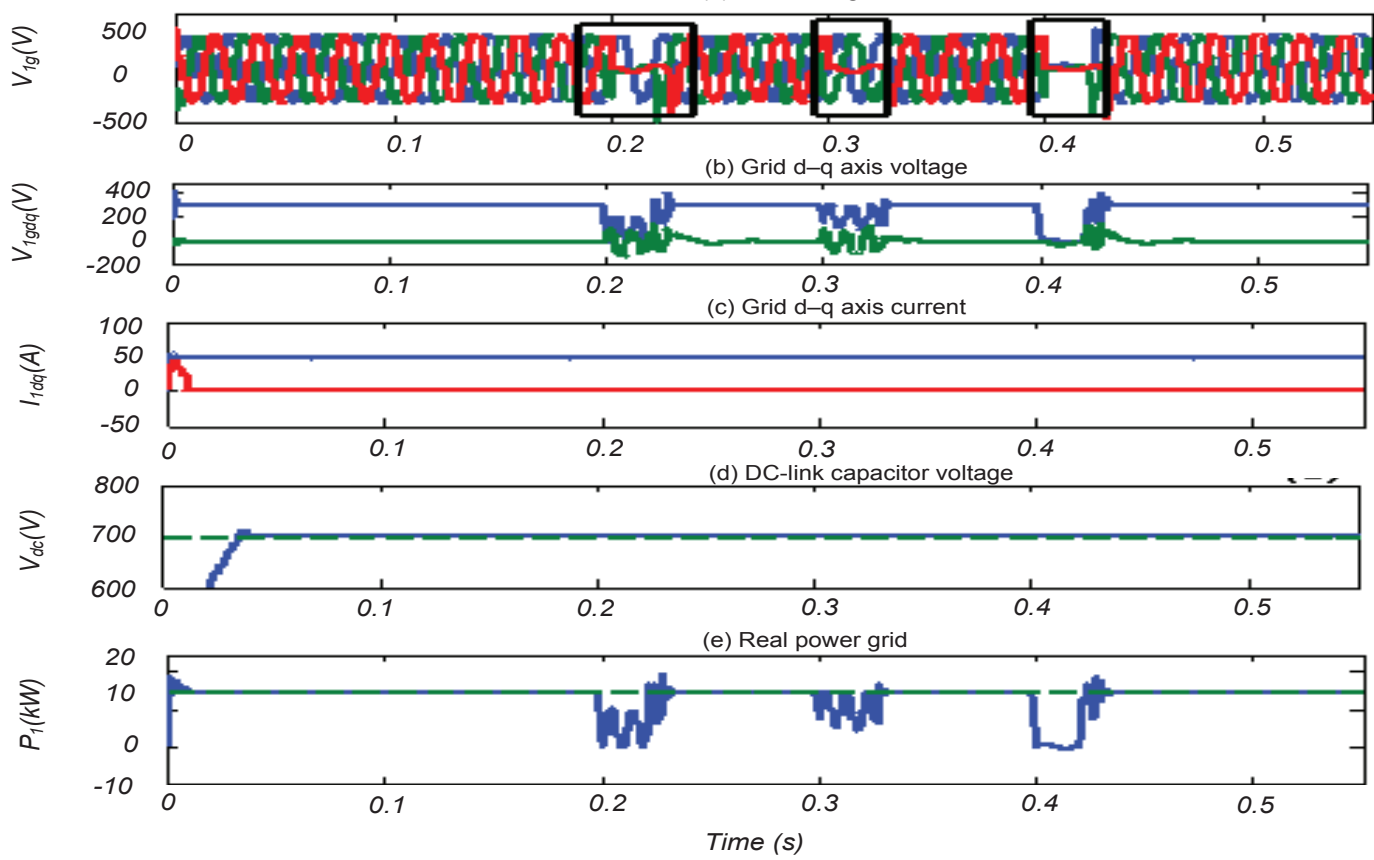

Fig. 20. Performance of the wind system in GCM operation. 


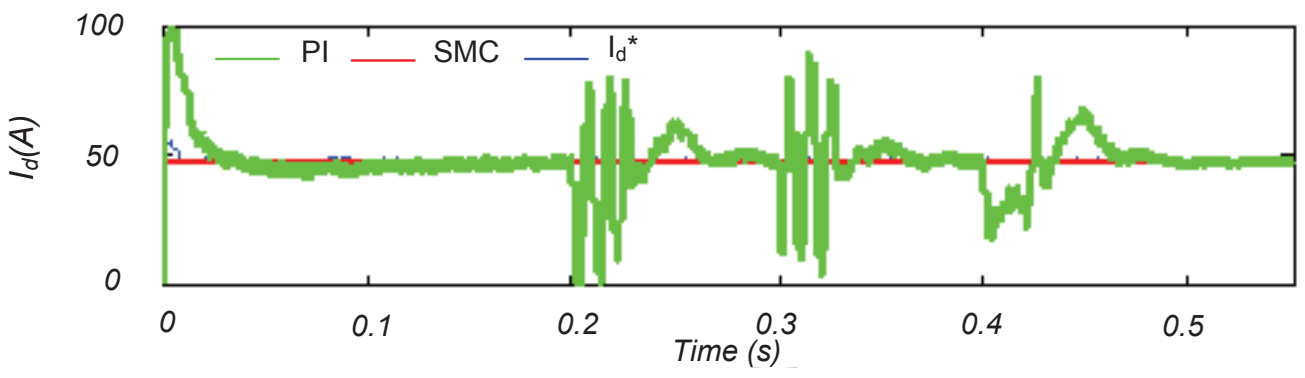

Fig. 21. Performance of direct current control.

Table 5. Steady-state performance of simulation results obtained by PI and SMC controller in GCM.

\begin{tabular}{llcc}
\hline Cases & Parameters & Pl controller & SMC controller \\
\hline \hline 1 & $T H D_{i}(0.2-0.3) \mathrm{s}$ & $11,52 \%$ & $3.87 \%$ \\
2 & $T H D_{i}(0.3-0.4) \mathrm{s}$ & $8.44 \%$ & $1.73 \%$ \\
3 & $T H D_{i}(0.4-0.5) \mathrm{s}$ & $12.67 \%$ & $4.73 \%$ \\
\hline
\end{tabular}

Fig.20 show the control performance of VSC in GCM, the waveforms of grid AC voltages at PCC ( $\left.v_{1 \text { gabd }}\right)$, the $d-q$ axes voltage $V_{1 d q}$, the reference and $d$-q axes components of current in the grid side, the measured and reference dc bus voltage (e) the measured and reference output power of the VSC are shown from Fig.20(a)-(e). As Fig.20 (a) shows the grid fault results in a significant drop in bus 1.

To verify the performance of the proposed SMC technique in this test comparative simulations including an established control system given by the PI controller. Fig. 21 indicates an examination of simulation results when the grid fault happens on the grid side. It can be seen from this assumption the proposed controller is superior to the traditional PI controller in this review. Table 5 summarizes the values of the indexes THD of the VSC output voltage acquired for every controller. It is observed that the average THD values are lower than $5 \%$ in all cases by utilizing SMC controller. Finally, it can be stated that the performance offered by the proposed SMC is greatly improved the power quality of the HRES compared to the PI controller.

\section{Conclusion}

This paper displays a contribution to the control performance of HRES composed of a variable wind speed turbine with PMSG, PV and BESS suitable for working in stand-alone and grid connected modes by utilizing a SMC approach. Approvals performed by reproduction in Matlab/Simulink have demonstrated the adequacy of the proposed methodologies for the control of the power converters under weather conditions, load types (balanced load, unbalanced load, and nonlinear load) and grid fault. Moreover, the traditional PI controller is compared with the proposed SMC controller. From these findings, we can say unequivocally that the proposed control technique drew a tremendous amount of interest thanks to its advantages such as robustness, fast steady-state error, and low harmonic distortion. Future investigations will be held on this technique.

\section{Acknowledgments}

This research was supported by the LANSER Laboratory/ Center for Research and Technology of Energy (CRTEn) and National Higher Engineering School of Tunis (ENSIT). 


\section{References}

Ahmed, N. A., Miyatake, M., \& Al-Othman, A. K. (2008). Power fluctuations suppression of stand-alone hybrid generation combining solar photovoltaic/ wind turbine and fuel cell systems. Energy Conversion and management, 49(10), 2711-2719.

Arul, P. G., Ramachandaramurthy, V. K., \& Rajkumar, R. K. (2015). Control strategies for a hybrid renewable energy system: A review. Renewable and sustainable energy reviews, 42, 597-608.

Bae, S., \& Kwasinski, A. (2012). Dynamic modeling and operation strategy for a microgrid with wind and photovoltaic resources. IEEE Transactions on smart grid, 3(4), 1867-1876.

Benadli, R. (2019). Improving grid connected hybrid generation system using an adaptive supertwisting sliding mode and predictive current control strategy. Journal of Control Engineering and Applied Informatics, 21(2), 64-75.

Benadli, R. (2020). Control and simulation of a standalone photovoltaic-wind with a fuel cell and battery storage. Journal of Electrical Engineering, 20(5), pp. 6-6.

Benadli, R., Khiari, B., \& Sellami, A. (2015). Three-phase grid-connected photovoltaic system with maximum power point tracking technique based on voltageoriented control and using sliding mode controller. In IREC2015 The Sixth International Renewable Energy Congress IEEE, pp. 1-6.

Bhandari, B., Lee, K. T., Lee, G. Y., Cho, Y. M., \& Ahn, S. $\mathrm{H}$. (2015). Optimization of hybrid renewable energy power systems: A review. International journal of precision engineering and manufacturing-green technology, 2(1), 99-112.

Bouharchouche, A., Berkouk, E. M., \& Ghennam, T. (2013). Control and energy management of a grid connected hybrid energy system PV-wind with battery energy storage for residential applications. In 2013 Eighth International Conference and Exhibition on Ecological Vehicles and Renewable Energies (EVER) IEEE, pp. 1-11.

Dali, M., Belhadj, J., \& Roboam, X. (2010). Hybrid solar-wind system with battery storage operating in grid-connected and standalone mode: control and energy management-experimental investigation. Energy, 35(6), pp. 2587-2595.

Dhar, S., \& Dash, P. K. (2016). Adaptive backstepping sliding mode control of a grid interactive PV-VSC system with LCL filter. Sustainable Energy, Grids and Networks, 6, pp. 109-124.

Dileep, G., \& Singh, S. N. (2017). An improved particle swarm optimization based maximum power point tracking algorithm for PV system operating under partial shading conditions. Solar Energy, 158, 1006-1015.

Do, T. D., Leu, V. Q., Choi, Y. S., Choi, H. H., \& Jung, J. W. (2012). An adaptive voltage control strategy of three-phase inverter for stand-alone distributed generation systems. IEEE Transactions on industrial Electronics, 60(12), 5660-5672.

Elgendy, M. A., Zahawi, B., \& Atkinson, D. J. (2011). Assessment of perturb and observe MPPT algorithm implementation techniques for $\mathrm{PV}$ pumping applications. IEEE transactions on sustainable energy, 3(1), 21-33.

Ghoddami, H., Delghavi, M. B., \& Yazdani, A. (2012). An integrated wind-photovoltaic-battery system with reduced power-electronic interface and fast control for grid-tied and off-grid applications. Renewable Energy, 45, pp. 128-137.

Jayalakshmi, N. S., Gaonkar, D. N., \& Nempu, P. B. (2016). Power control of PV/fuel cell/ supercapacitor hybrid system for stand-alone applications. International Journal of Renewable Energy Research (IJRER), 6(2), 672-679.

Khadem, S. K., Basu, M., \& Conlon, M. (2010). Power quality in grid connected renewable energy systems: Role of custom power devices, Phys. Rev. 47, 777-780.

Kim, S. K., Jeon, J. H., Cho, C. H., Ahn, J. B., \& Kwon, S. H. (2008). Dynamic modeling and control of a gridconnected hybrid generation system with versatile power transfer. IEEE transactions on industrial electronics, 55(4), 1677-1688.

Linh, N. T. (2009, May). Power quality investigation of grid connected wind turbines. In 2009 4th IEEE Conference on Industrial Electronics and Applications IEEE, pp. 2218-2222.

Luna-Rubio, R., Trejo-Perea, M., Vargas-Vázquez, D., \& Ríos-Moreno, G. J. (2012). Optimal sizing of renewable hybrids energy systems: A review of methodologies. Solar energy, 86(4), pp.1077-1088.

Madaci, B., Chenni, R., Kurt, E., \& Hemsas, K. E. (2016). Design and control of a stand-alone hybrid power system. International journal of hydrogen energy, 41(29), pp. 12485-12496.

Malla, S. G., \& Bhende, C. N. (2014). Voltage control of stand-alone wind and solar energy system. International Journal of Electrical Power \& Energy Systems, 56, pp. 361-373.

Rezkallah, M., Hamadi, A., Chandra, A., \& Singh, B. (2015). Real-time HIL implementation of sliding 
mode control for standalone system based on PV array without using dumpload. IEEE Transactions on Sustainable Energy, 6(4), pp. 1389-1398.

Rezvani, A., Khalili, A., Mazareie, A., \& Gandomkar, M. (2016). Modeling, control, and simulation of grid connected intelligent hybrid battery/photovoltaic system using new hybrid fuzzy-neural method. ISA transactions, 63, pp. 448-460.

Tan, S. C., Lai, Y. M., \& Chi, K. T. (2008). General design issues of sliding-mode controllers in DCDC converters. IEEE Transactions on Industrial Electronics, 55(3), 1160-1174.
Teodorescu, R., \& Blaabjerg, F. (2004). Flexible control of small wind turbines with grid failure detection operating in stand-alone and gridconnected mode. IEEE transactions on power electronics, 19(5), pp. 1323-1332.

Wang, Y. X., Qin, F. F., Ou, K., \& Kim, Y. B. (2015). Sliding-mode-control-based DC/DC converters design and implementation for hybrid proton exchange membrane fuel cell/battery power system. In 2015 9th International Conference on Power Electronics and ECCE Asia (ICPE-ECCE Asia), pp. 2155-2160. 